\title{
Design and Implementation of a Control Strategy for Microgrid Containing Renewable Energy Generations and Electric Vehicles
}

\author{
Mingchao Xia, Xuanhu He, and Xiaoqing Zhang \\ School of Electrical Engineering, Beijing Jiaotong University, No. 3 Shang Yuan Cun, Hai Dian District, Beijing 100044, China \\ Correspondence should be addressed to Mingchao Xia; mchxia@bjtu.edu.cn
}

Received 13 December 2012; Accepted 12 May 2013

Academic Editor: Massimo Scalia

Copyright (C) 2013 Mingchao Xia et al. This is an open access article distributed under the Creative Commons Attribution License, which permits unrestricted use, distribution, and reproduction in any medium, provided the original work is properly cited.

\begin{abstract}
Large amount of such renewable energy generations as wind/photovoltaic generations directly connected to grid acting as distributed generations will cause control, protection, security, and safety problems. Microgrid, which has advantages in usage and control of distributed generations, is a promising approach to coordinate the conflict between distributed generations and the grid. Regarded as mobile power storages, batteries of electric vehicles can depress the fluctuation of power through the point of common coupling of microgrid. This paper presents a control strategy for microgrid containing renewable energy generations and electric vehicles. The control strategy uses current control for renewable energy generations under parallel-to-grid mode, and uses master-slave control under islanding mode. Simulations and laboratory experiments prove that the control strategy works well for microgrid containing renewable energy generations and electric vehicles and provides maximum power output of renewable energy and a stable and sustainable running under islanding mode.
\end{abstract}

\section{Introduction}

As long as the growing demands for green, clean, and highquality energy supplies, renewable energy generations such as solar and wind power acting as distributed generations (DGs) are gaining more and more attentions. Discussions about grid of the future on 2012 International Council on Large Electric Systems (CIGRE2012) pointed that new technologies, new participants, and new market environments are leading the traditional value chain of "fossil energy sourcegrid transmission end user" to a new value chain adopting renewable energy generations and distributed generations, power storages, and electric vehicles (EVs) [1]. To some extent, DGs can improve power quality, power reliability, economy, and flexibility along with impacts to grid caused by its fluctuant power output. The key factor of using DGs lies on how to coordinate DGs with main grid to stable and reliable running. Concept of microgrid or minigrid-a small grid that integrates DGs and loads to form a controllable grid which can provide power supply both under parallel-to-grid and islanding mode-was proposed and adopted by many countries and power companies.
Control strategies of microgrid containing control of grid and control of DGs must coordinate DGs with main grid under parallel-to-grid mode and coordinate different DGs with loads under islanding mode. Commonly used control methods of microgrid include peel-to-peel control, masterslave control, and multiagent control, while control methods of DGs include current control method, voltage control method, and droop control method. The main concern of control method under parallel-to-grid mode is how to depress the fluctuations of power outputs of DGs while using the maximum amount of DG energy such as wind power or solar power. The main concern of control method under islanding mode is how to coordinate power outputs of different DGs with loads to keep stable voltage and frequency level for constant running.

Electric vehicles regarded as a new traffic method have been paid more common attention. While commonly treated as loads, batteries of electric vehicles can provide power support when necessary-which is called vehicle-to-grid (V2G) mode [2]. V2G mode of electric vehicles can reduce the need of common power storages in microgrid by depressing fluctuation of power and providing emergency power supply. 
Compared with common battery storage, batteries of electric vehicles can be regarded as mobile power storage devices: mobility of vehicles cause the capacity change of charging and discharging along with the unpredictability of charging or discharging status; transport demand, charging methods (charge/replace), and charging speed (fast/slow) of vehicles cause differences in control and external characteristics.

To coordinate DGs and grid, considering the instability and unpredictability of DGs and EVs, a control strategy for microgrid containing renewable energy generations and electric vehicles was presented in this paper. Control methods of microgrid were analyzed and studied to propose a comprehensive control strategy for microgrid with DGs and EVs. The control strategy uses MPPT current control for renewable energy generations under parallel-to-grid mode and uses master-slave control which elects battery storages as master while other DGs and EVs as slaves under islanding mode. A common structure microgrid with DGs, battery storage, and EVs was built both in simulation and laboratory experiment. Simulations and laboratory experiments prove that the control strategy works well for microgrid containing renewable energy and EVs and provides maximum power output of renewable energy and a stable and sustainable running under islanding mode.

\section{Distributed Generations and Microgrid}

Generally, distributed generations (DGs) refer to such environment friendly or renewable power generation devices as photovoltaic, wind power, fuel cells or microgas turbine which are located near loads and capacity of tens of kilowatts to several megawatts. DGs can improve power quality and power reliability with the following characteristics [3]. (1) Power Generation near loads without step-up and stepdown transformer and load distance transmission will reduce construction and maintenance cost, reduce power loss of transmission and improve efficiency. (2) Immune to faults in transmission, and transformation system which will improve power reliability and power quality. (3) Immune to the interferes of regional voltage and frequency fluctuations, preventing regional failure develop to blackouts.

Commonly adopted DGs are microgas turbine, fuel cell, wind power, photovoltaic, and power storage devices. Microgas turbine burns gas, methane, or gasoline with total efficiency up to $75 \%$ under thermoelectricity cogeneration mode which is a promising commercial DG [4]. Fuel cell transforms the fuel chemical energy into the electrical energy through the electrode reaction with little emission, which has higher efficiency than traditional power plant [5]. Nevertheless, gas turbine and fuel cell need primary energy sources such as gas or fuel to produce electric power. On the point of renewable and sustainable energy view, micro gas turbine and fuel cell are not suitable choices while wind power and solar power are more suitable and feasible.

2.1. Wind Power Generation. Wind power generation uses wind power to produce electric power which has features of environment friendly and zero emission and now has mature

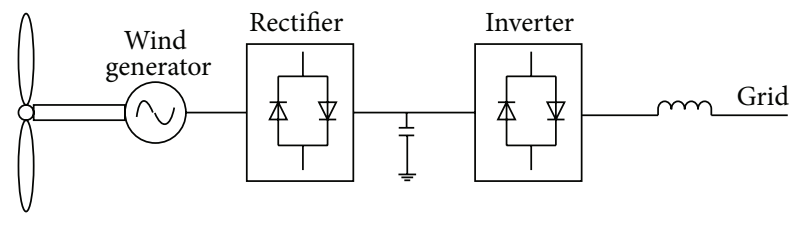

FIGURE 1: Wind power generation system structure.

technology of single generator capacity of $2500 \mathrm{~kW}$. As shown in Figure 1, wind generators are mostly asynchronous generators which produce frequency-varying AC power and need rectifier and inverter to convert to grid frequency and parallel in grid.

Paralleled in through an inverter, wind power generation will consume reactive power while producing active power, and wind power generation is normally combined with power storage, photovoltaic generation, diesel generator, or reactive power generation devices. Operation modes of wind power generation are mainly two types: (1) stand alone operation mode, which uses small wind generators to charge battery storages and through an inverter to support end user or medium wind generators combined with diesel generators or photovoltaics to form hybrid power supply; (2) operation with grid mode, which uses large wind generators capacity range $200 \mathrm{~kW}$ to $2500 \mathrm{~kW}$ to form wind power farm as power source of grid.

Power output of wind power generation is closely related to the rotating speed of generator under certain wind speed. Figure 2 shows an example relation of torque and rotating speed (a) and relation of power and rotating speed (b) at two wind speeds of $v_{1}$ and $v_{2}$ [6]. As power output depends on the product of torque $T$ and rotating speed $\omega$, the rotating speed of maximum power output is not the same to that of maximum torque. Commonly, wind power generation uses a speed-varying control system called maximum power point tracking (MPPT) which controls the wind generator works on the speed point of maximum power output [7].

2.2. Photovoltaic Generation. Photovoltaic generation (PV), based on the photovoltaic effect of photovoltaic cell to convert solar energy to DC energy, has features of environment friendly, easy maintenance, zero emission, and low cost. Operation modes of PV are mainly two types: (1) islanding mode, that power system with PV is not connected to public power grid, is commonly used for areas far from public power grid such as an island; (2) parallel-in mode, that PV is paralleled to public power grid. This mode can use photovoltaic generations as mass power production and is the most used mode in the world [8-10].

Output voltage and current of photovoltaic cell change with light intensity and temperature. Figure 3 shows an example relation of current and voltage (a) and relation of power and voltage (b) of PV at different light intensities. Figure 4 shows an example relation of current and voltage (a) and relation of power and voltage (b) of PV at different temperatures. At certain light intensity and temperature, photovoltaic cell can work at a different voltage, while 


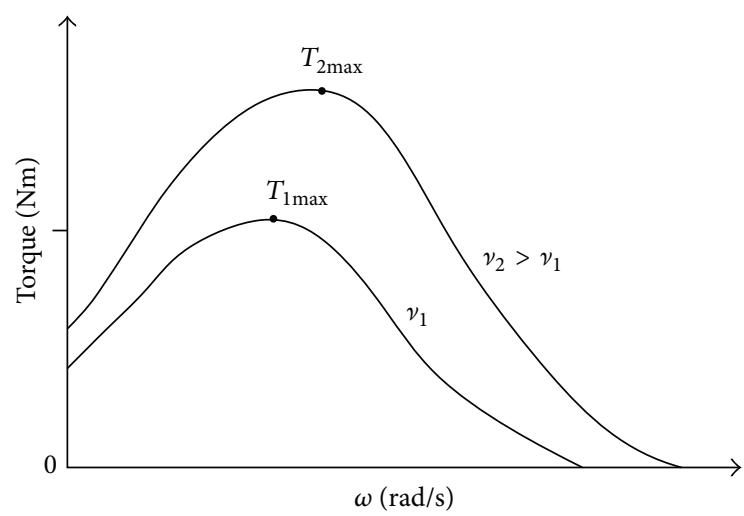

(a)

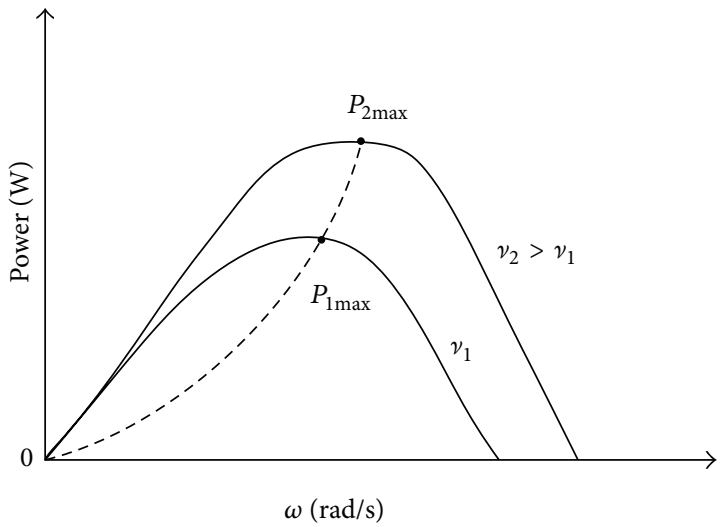

(b)

FIGURE 2: Relation of torque/speed and power/speed of wind generator at two wind speeds.

only at a certain voltage, the output power of photovoltaic cell reaches the maximum output. Similar to wind power, photovoltaic generation uses MPPT control of voltage to control the photovoltaic cell works on the voltage point of maximum power output [11].

2.3. Power Storage Devices and Electric Vehicles. Acting as a distributed generation, output power is affected by weather conditions (wind/light) wind power generation and photovoltaic generation are intermittent power supply which cannot meet the load demand full time. Thereby, power storage devices are widely used in distributed generation for continuous power supply. Effects of power storage devices in distributed generation are as follows [12]. (1) Power storage devices can depress load wave by charging when load is low and discharging when load is high. (2) Active power and reactive power outputs of power storage devices can change rapidly, which can damp the power and frequency of a system to keep the system stable. (3) Tracking ability of power storage devices can keep distributed power sources working at maximum power point and improve power efficiency. There are many types of power storage devices such as battery storage, super-capacitor storage, flying-wheel storage, and

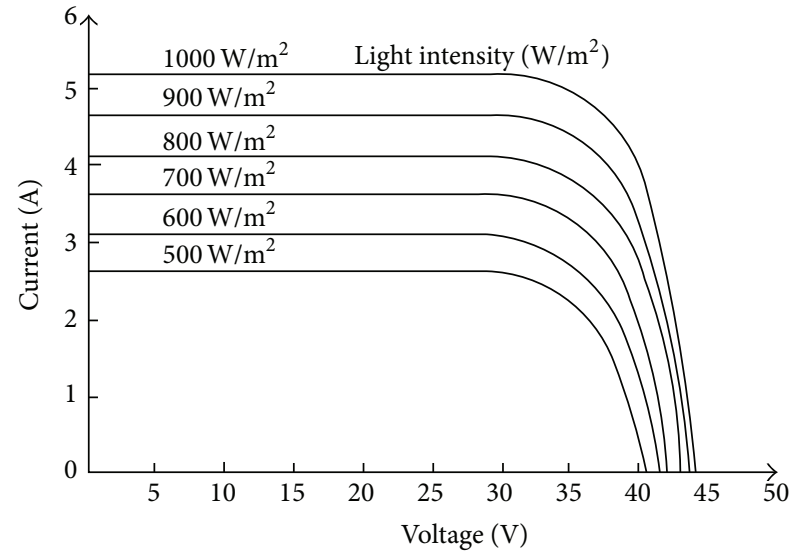

(a)

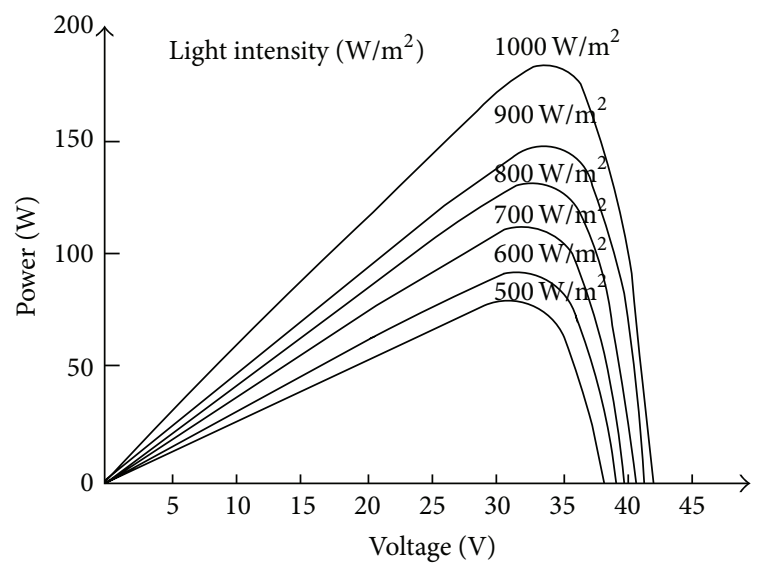

(b)

FIgURE 3: Relation of $I-V / P-V$ of PV cell at different light intensities.

hydroplant, while the most widely used power storage device is battery storage.

As the development and spread of electric vehicles, influence of batteries especially large capacity batteries of EVs connected to grid is gaining more and more attention. Batteries of electric vehicles can provide power support when necessary-which is called vehicle-to-grid (V2G) mode [2, 13]. Compared with common batteries, batteries of EVs can be regarded as mobile power storage devices: the coupling point is mobile; the status and capacity of charging or discharging is indeterminate. When connected to grid, batteries of EVs can act as common battery storages and reduce the demand capacity of common power storages. As the growth of EVs, it is necessary to take full advantage and rational use of batteries of EVs.

2.4. Microgrid. Traditional power distribution grid distributes power to end user through a branchy, radialized network which transfers power in single direction. Single DG directly connected to power distribution grid will change the power flow direction and cause analysis, control, and protection problem of power distribution grid. Restrain and isolate methods are commonly adopted by a grid to decrease 


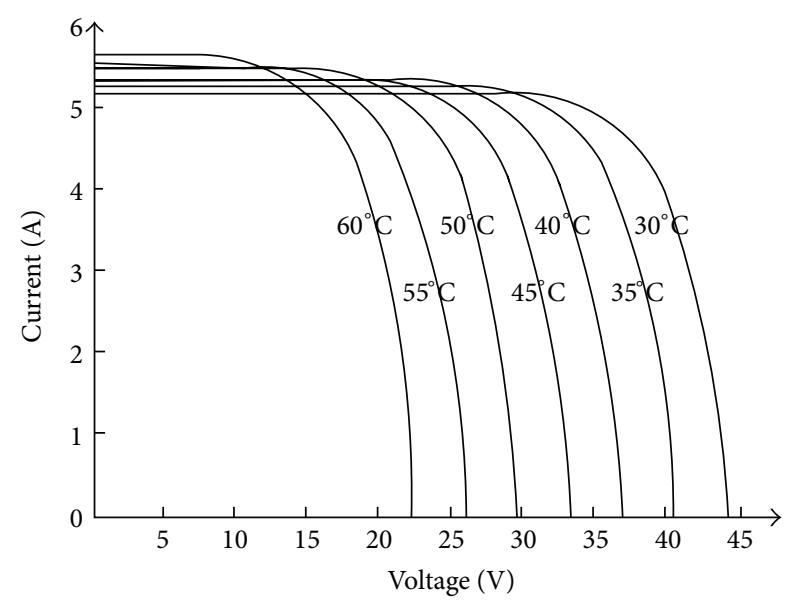

(a)

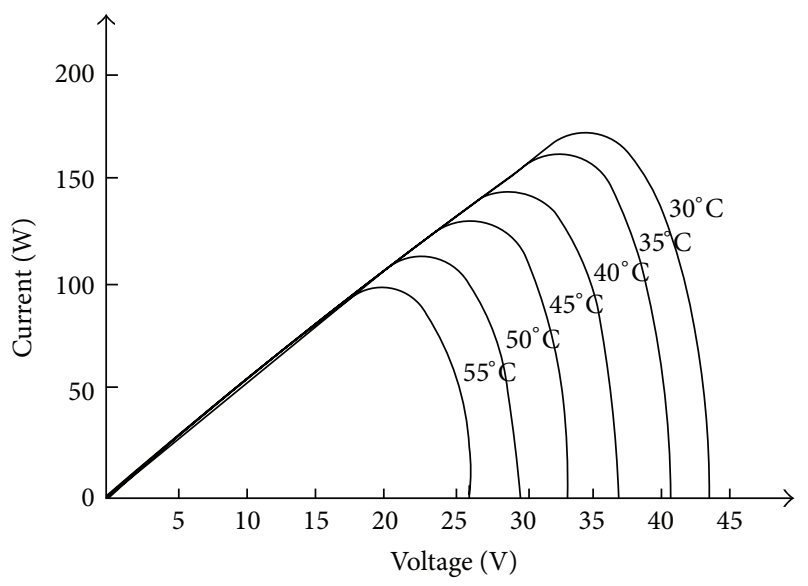

(b)

FIgURE 4: Relation of $I-V / P-V$ of PV cell at different temperatures.

the impact of DGs. A concept of combined DGs with loads to form a so-called microgrid to coordinate grid and DGs was proposed $[14,15]$. Although different concepts of microgrid were proposed by different countries according to their own instances, goals and patterns of these concepts are similar, where the concept proposed by Consortium for Electric Reliability Technology Solutions (CERTS) was most widely adopted: "an aggregation of loads and microsources operating as a single system providing both power and heat. The majority of the microsources must be power electronic based to provide the required flexibility to insure operation as a single aggregated system. This control flexibility allows the CERTS MicroGrid to present itself to the bulk power system as a single controlled unit that meets local needs for reliability and security." [15]. Microgrid usually consists of DGs, power storage devices, power electronic devices (such as inverter, solid state switch), and loads. Microgrid has following the characteristics: (1) Microgrid provides an efficient way for DGs to parallel in utility grid, and inherit the advantages of DG; (2) microgrid can switch to island mode on utility grid failure, and does not affect the security and safety of utility grid; (3) plug-and-play ability of DG connection; (4) improve efficiency of DG by combined heat and power (CHP) or combined cold heat and power (CCHP), (5) damping effect to voltage and frequency fluctuation.

2.5. Microgrid Containing Renewable Energy and Electric Vehicles. Single EV has little effect on the utility grid even under V2G mode. But when a certain number of electric vehicles are paralleled in the grid, they will inevitably affect the utility grid. Charging station was adopted in China for individual and public EV charging. A microgrid scheme which combines photovoltaic, power storage, and EV charging station together was proposed by Beijing Jiaotong University (BJTU) and implemented in laboratory where the microgrid with a simplified structure can be regarded as a submicrogrid in the modified structure of CERTS microgrid as shown in Figure 5, where the primary microgrid is connected with the distribution grid through the circuit breaker; the submicrogrid with EVs is connected with the bus through the feeder just as other microsources.

The submicrogrid with EVs is a simplified microgrid with 1 concentrated busbar as shown in Figure 6 where the busbar can be a DC busbar or AC busbar, while DC busbar will need a large capacity bidirectional power converter at the point of common coupling (PCC), and AC busbar is a more suitable solution for charging station. In Figure 6, DGs and power storage devices are located near charging station, battery storages act as fixed power storage while EVs act as mobile storage.

\section{Control Methods}

3.1. Control Methods of Microsources. Control methods of microgrid consist of microsource control and the grid control. Most DGs are using MPPT control to reach their maximum power output and through a converter/inverter connected to microgrid busbar. As the system in Figure 6, with an AC busbar, microsources such as wind power and battery storage are connected with inverters. Control methods of microsources in the simplified system of microgrid with renewable energy and EVs as in Figure 6 focus on control methods of microgrid inverters. The common used control methods of microgrid inverter include current control method, voltage control method, and droop control method [16].

3.1.1. Current Control Methods. Current control method of microgrid inverter uses the output current as control signal which produces current of the same frequency and same phase angle with the grid voltage to provide power. Under current control method micro sources can be regarded as controllable current source with large inner impedance. Basic control diagram of current control method is shown as Figure 7 where $i_{0}$ is the output current of inverter, $i_{\text {ref }}$ is the setting value of current.

There are two ways of current control method: indirect current control and direct current control. Indirect current control uses the setting current, voltage vector of PWM to 


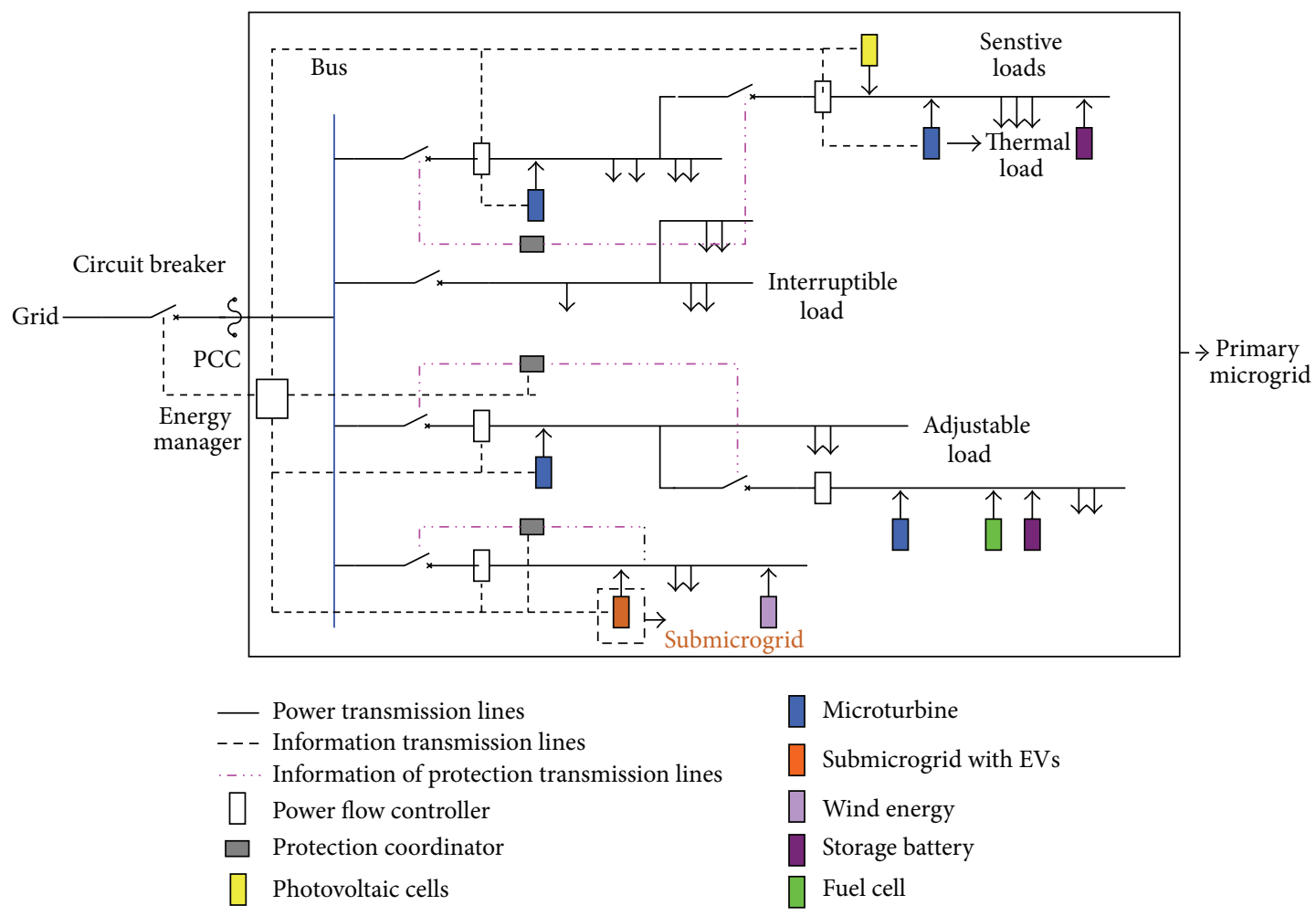

FIGURE 5: Modified structure of CERTS microgrid.

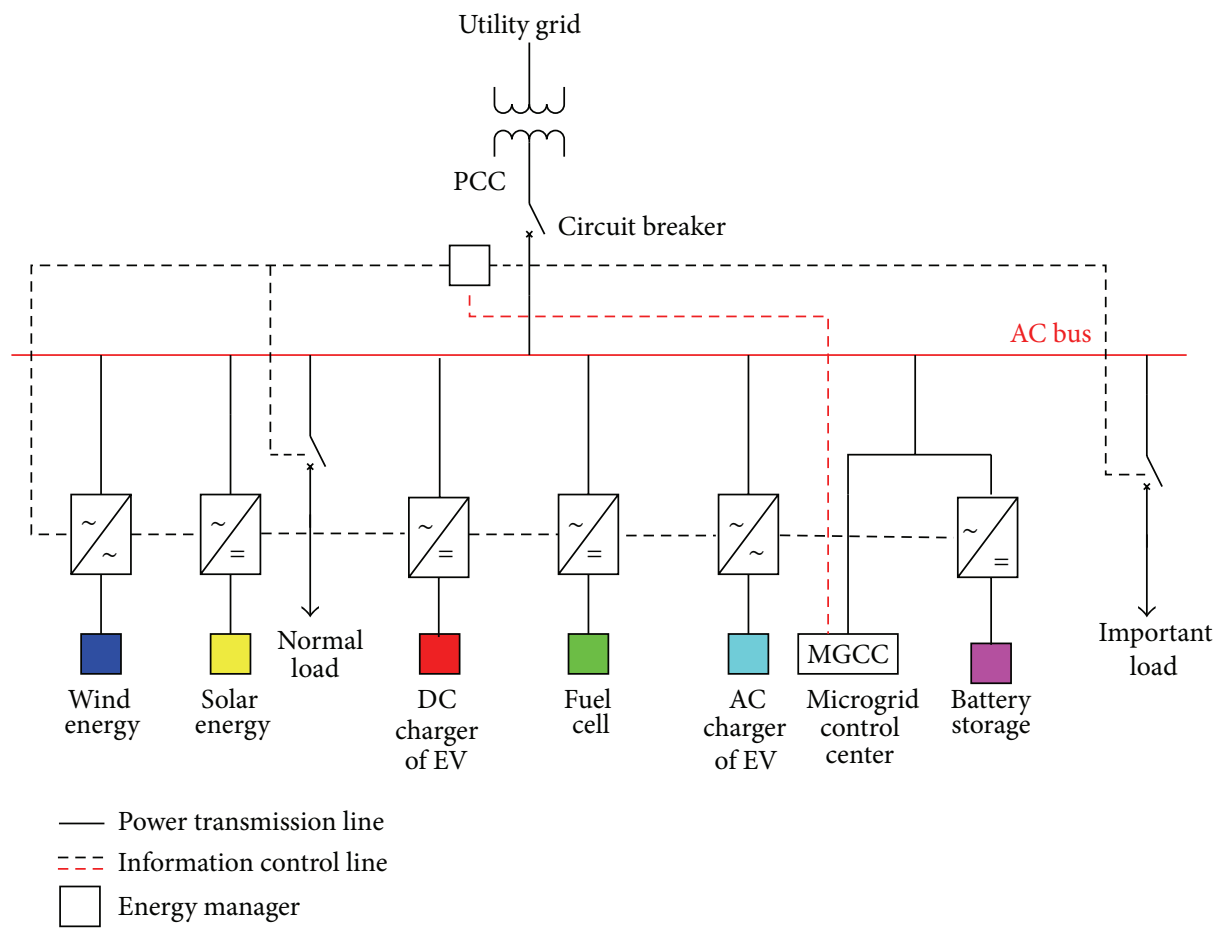

FIGURE 6: Submicrogrid with EV. 


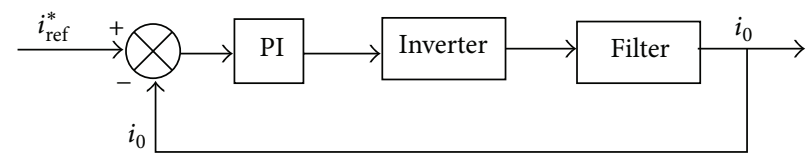

FIgURE 7: Basic diagram of current control method.

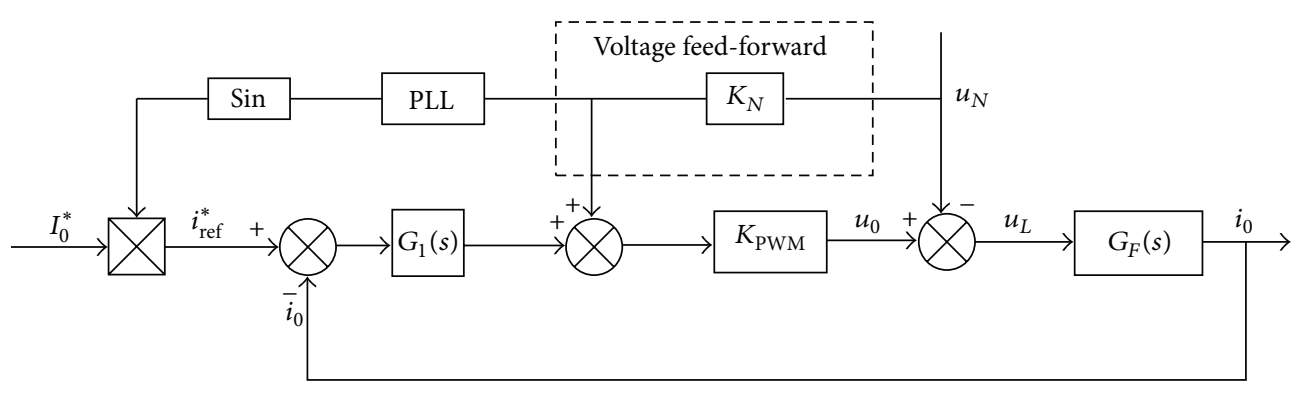

FIGURE 8: Diagram of direct current control with voltage feed-forward.

form closed-loop control which through voltage control to achieve current control. This method is simple and is no need of current detection, but it has disadvantages of slow dynamic response and transient DC-drift and is affected by the quality of grid voltage.

As shown in Figure 8, direct current control directly uses current as feedback to achieve synchronous current with grid voltage, where $i_{0}$ is current output of inverter, $u_{N}$ is grid voltage, $K_{\mathrm{PWM}}$ is the equivalent gain coefficient of inverter, $G_{1}(s)$ is the transfer function of current regulator usually use PI regulation, $G_{F}(s)$ is equivalent transfer function of filter, PLL is a phase locked loop module tracking the frequency and phase of grid voltage to keep the frequency and phase of output current same to them. A voltage feed-forward module was introduced to eliminate current fluctuation caused by grid voltage fluctuation $[17,18]$ where in Figure $8 K_{N}$ is the coefficient of voltage feed-forward. The direct current control with voltage feed-forward was adopted in this paper.

3.1.2. Voltage Control Method. Voltage control method of microgrid inverter uses the output voltage as the control signal which produces voltage of the same frequency and the same phase angle with the grid voltage to provide power. Under voltage control method, micro sources can be regarded as controllable voltage source with small inner impedance. Basic control diagram of voltage control method is shown as in Figure 9 where $i_{0}$ is the output current of inverter, $V_{g}$ is the voltage of grid, and $V_{\text {ref }}$ is the setting voltage value of inverter.

Voltage control method as in Figure 9 uses dual control loop-outer loop of voltage to keep voltage stable and inner loop of current to improve dynamic response performance and restrain fluctuation [19]. Compared with current control methods, voltage control method has advantages of good dynamic performances, high steady state accuracy, robust to nonlinear load, and low harmonics. Inverter under voltage control mode provides reference voltage and frequency to microgrid in islanding and is also called a voltage source converter (VSC); other inverts can use the voltage of VSC as a reference and run in desired mode. While microgrid under parallel-to-grid mode, micro source in VSC mode is a voltage source that must coordinate with the main source of utility grid to keep synchronization. Commonly VSC mode is more suitable for the main micro source in islanding mode microgrid.

3.1.3. Droop Control Methods. Micro sources in parallelto-grid mode microgrid usually work in current control mode, while another mode called droop control method is also used to make a microgrid work more like traditional power grid. Droop control method decouples power and voltage and frequency to form droop style $P$ - $f$ (active power-frequency) and $Q-V$ (reactive power-voltage) or $P$ $V$ and $Q-f$ micro source output characteristics like traditional synchronous generator; thus, the traditional grid control methods can be applied in microgrid [20]. Under droop control method, inverter adopts an inner droop curve according to its capacity and type of micro source and produces voltage with amplitude and frequency determined by its active and reactive power output. Control diagram of droop control method is as shown in Figure 10 where $P_{N}, I_{N}$, and $f_{N}$ are the rated power, current, and frequency of micro source under droop control mode. Droop control module calculates the voltage amplitude and frequency at input $P$ and $Q$ according to its inner droop curve. Voltage combination module provides reference voltage at input $f$ and $V$, and the dual loop control of voltage and current module provide PWM to drive the inverter. Droop control method makes micro sources work like traditional synchronous generators - which are easy to control and dispatch. Nevertheless, it also makes micro sources only work well when voltage and frequency are near rated value; unsuitable droop curves will make system unstable, bad system dynamic performance, and easy to swing because of low damping effects. 


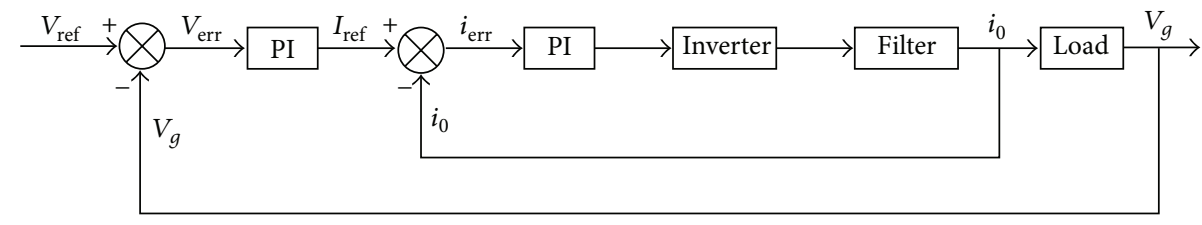

FIGURE 9: Basic diagram of voltage control method.

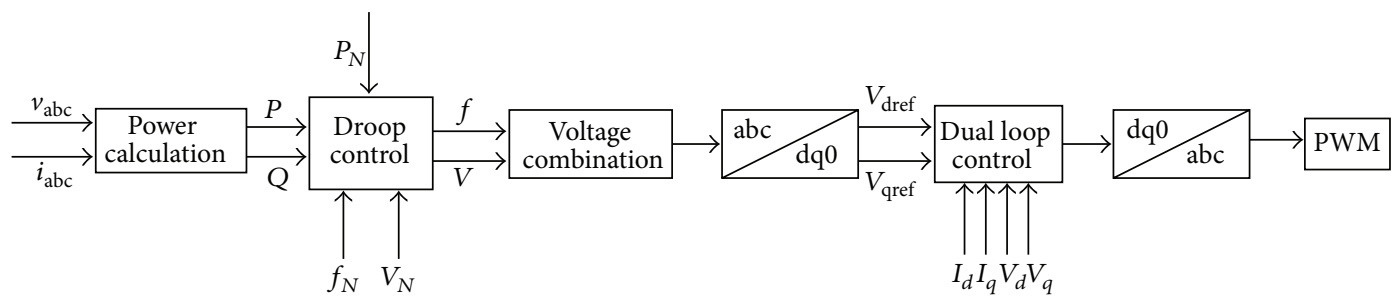

FIgURE 10: Control diagram of droop control method.

\subsection{Grid Control Methods of Microgrid}

3.2.1. Peer-to-Peer Control. Under peer-to-peer control method, each micro source acts as a "peer" and equally in microgrid. Each micro source participates in the regulation of voltage and frequency according to their own inner control $[21,22]$. Commonly peer-to-peer control is based on the droop control of micro sources which decouple frequency and voltage to active and reactive power. Micro sources are initialized at rated frequency $f 0$ and inner potential E0, while load changes, active power, and reactive power flow in microgrid change accordingly; with that, active power and reactive power outputs of each micro source will change; coordinated by frequency and voltage, system will reach a new balanced point by droop character. This is similar to primary frequency control of synchronous generators. The peer-to-peer grid control method of microgrid has the advantages of simple, easy-to-implement, local controlled (no need of communication), plug-and-play, and easy-tomodify. But this method cannot treat the restoration problem of voltage and frequency caused by severe disturbance of power which is usually regulated by secondary frequency control in traditional synchronous generators [21].

3.2.2. Master-Slave Control. Under master-slave control method, one or more micro sources are elected as a master source of microgrid which provides reference voltage and frequency, other micro sources act as a slave source [23]. Masterslave control mode is mostly used for microgrid in islanding mode, while in parallel-to-grid mode the utility grid is master and all micro sources are slaves. Using master-slave control mode in islanded microgrid, the master source elected must have the ability of fast changing to voltage control mode, good voltage and frequency regulation character, and stable and controllable power output. Commonly elected master sources are power storage devices such as battery storage, micro gas turbines, or fuel cells.

The master-slave grid control method of microgrid has the advantages of simple, good voltage, and frequency regulation character and dynamic response. But the performance of master-slave control method rely on master source: master source needs rapid change to voltage control mode when islanding happens to microgrid; voltage and frequency are regulated by master source where master source failure will cause whole microgrid failure; multimaster sources will cause current loop; fluctuations of power are balanced mainly by main source which require certain power reservation of main source.

3.3. Control Methods Adopted. Direct current control method with voltage feed-forward as in Figure 8 was adopted for micro sources (DGs, battery discharging, and V2G) control when microgrid paralleled to utility grid in this paper, where DGs work as current sources. Master-slave grid control method is adopted for microgrid in islanding mode, and battery storage work in voltage control mode was adopted as main source, while other micro sources still work in current control mode.

\section{Simulations and Laboratory Implementation}

Simulations of microgrid with renewable energy and EV were carried out, and a laboratory platform of microgrid was established. Control methods in 3.3 were used both in simulation and laboratory platform. An islanding detection method of over/load voltage and over/low frequency was adopted for control mode change, and a load shedding method was adopted.

4.1. Simulation Model and Results. A simulation model as in Figure 11 was built in MATLAB/simulink according to the parameters of the laboratory platform where the utility grid is a $380 / 220 \mathrm{~V}$ system, DG1 is a $25 \mathrm{~kW}$ photovoltaic cell (PV), DG2 is a $50 \mathrm{kWh}$ lithium battery storage, DG3 is a $18 \mathrm{~kW} \mathrm{EV}$, load 1 is a load of $10 \mathrm{~kW}$, load 2 is a load of $10 \mathrm{~kW}+1.5 \mathrm{kVar}$, and load 3 is a $25 \mathrm{kVA}$ fluctuant and interruptible load. 


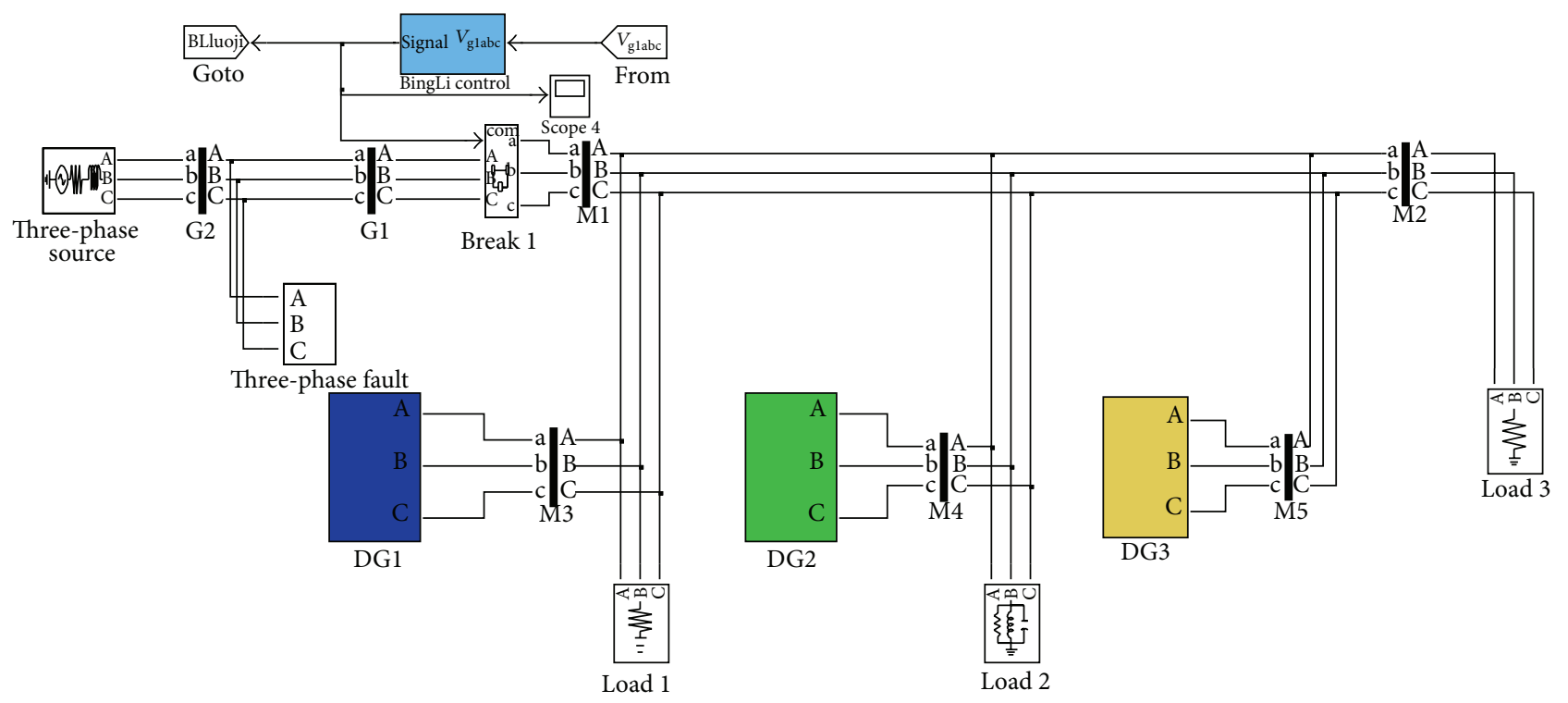

\begin{tabular}{|c|}
\hline Discrete, \\
$T_{s}=5 e-005 \mathrm{~s}$. \\
\hline Powergui
\end{tabular}

FIGURE 11: Simulation mode of microgrid with PV and EV.

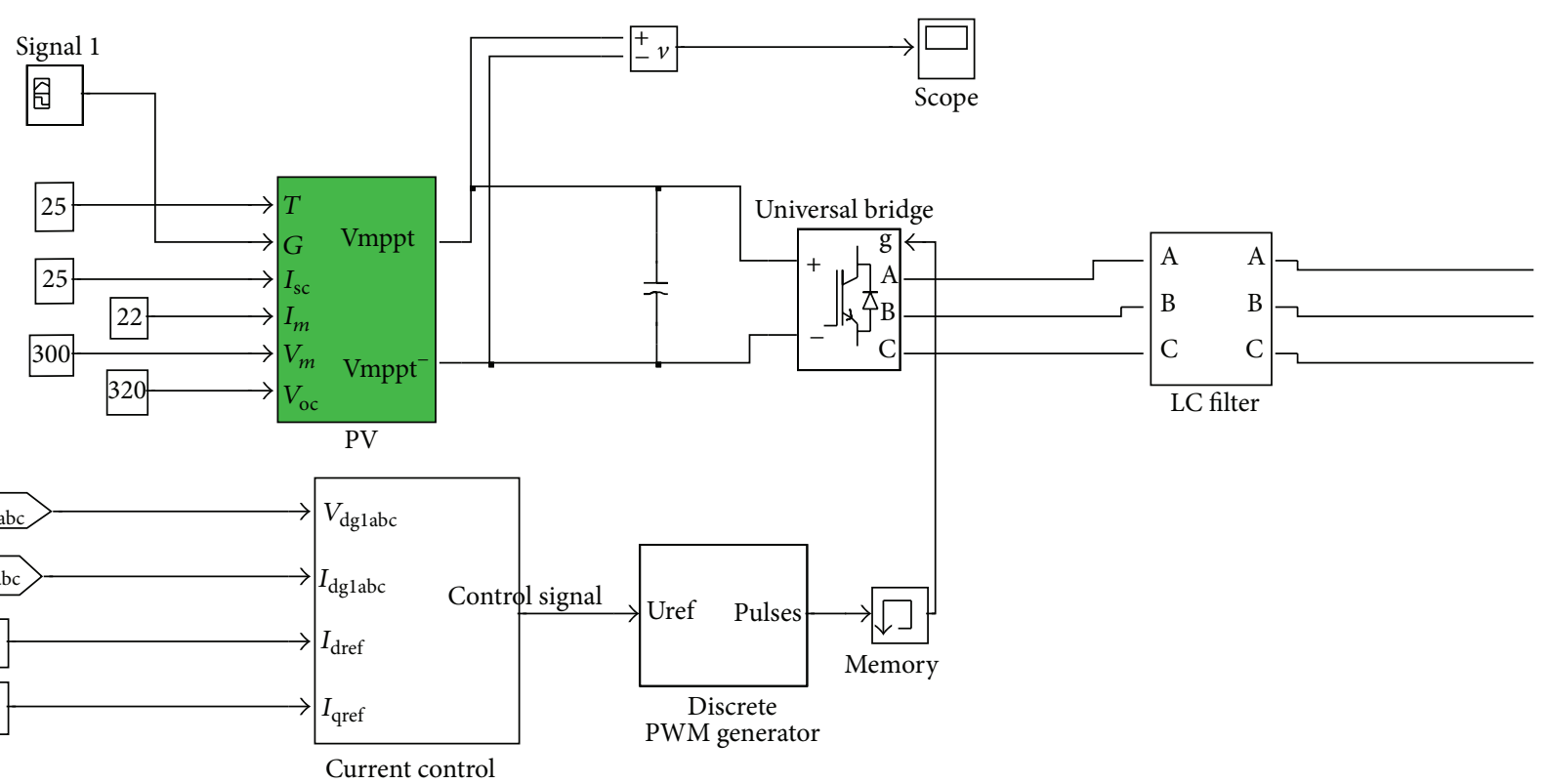

FIGURE 12: Simulation model of PV (DG1).

DG1 in Figure 11 is the simulation model of PV as shown in Figure 12 which adopts the PV array model used in [24] and MPPT control in [25]. Inverter of DG1 works in current control mode. DG2 in Figure 11 is the simulation model of battery storage as shown in Figure 13 which uses battery module in MATLAB /simulink. Converter of DG2 works in current control mode when microgrid paralleled to grid and works in voltage control mode as main power source when microgrid is islanded.

Figure 14 shows the simulation model of EV (DG3) in Figure 11. SOC and capacity of battery was adopted with $10 \%$ fluctuation normal distributed. A uncontrolled rectifier was adopted for battery charging, and a current control mode was adopted for battery discharging. 


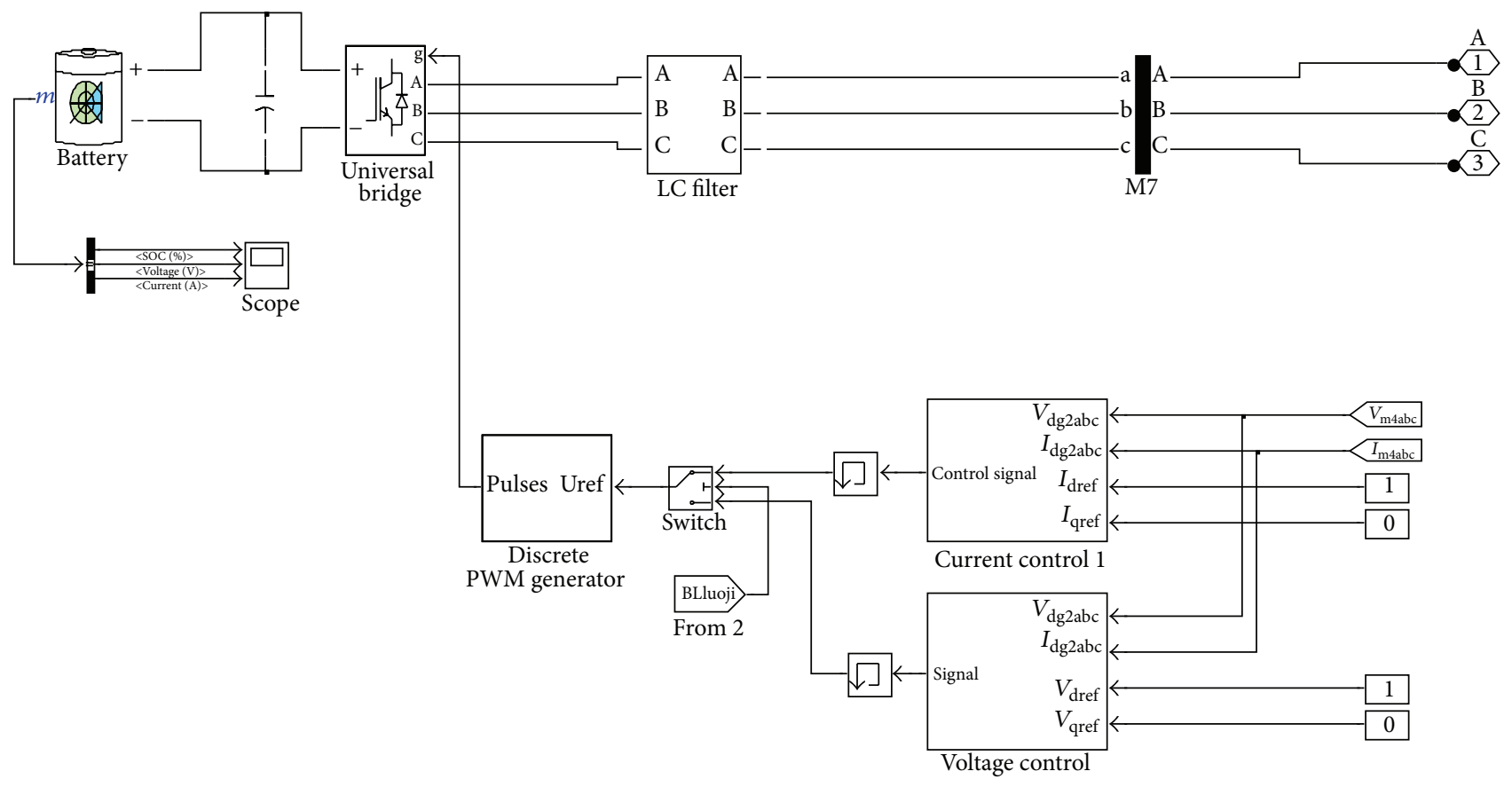

FIGURE 13: Simulation model of battery (DG2).

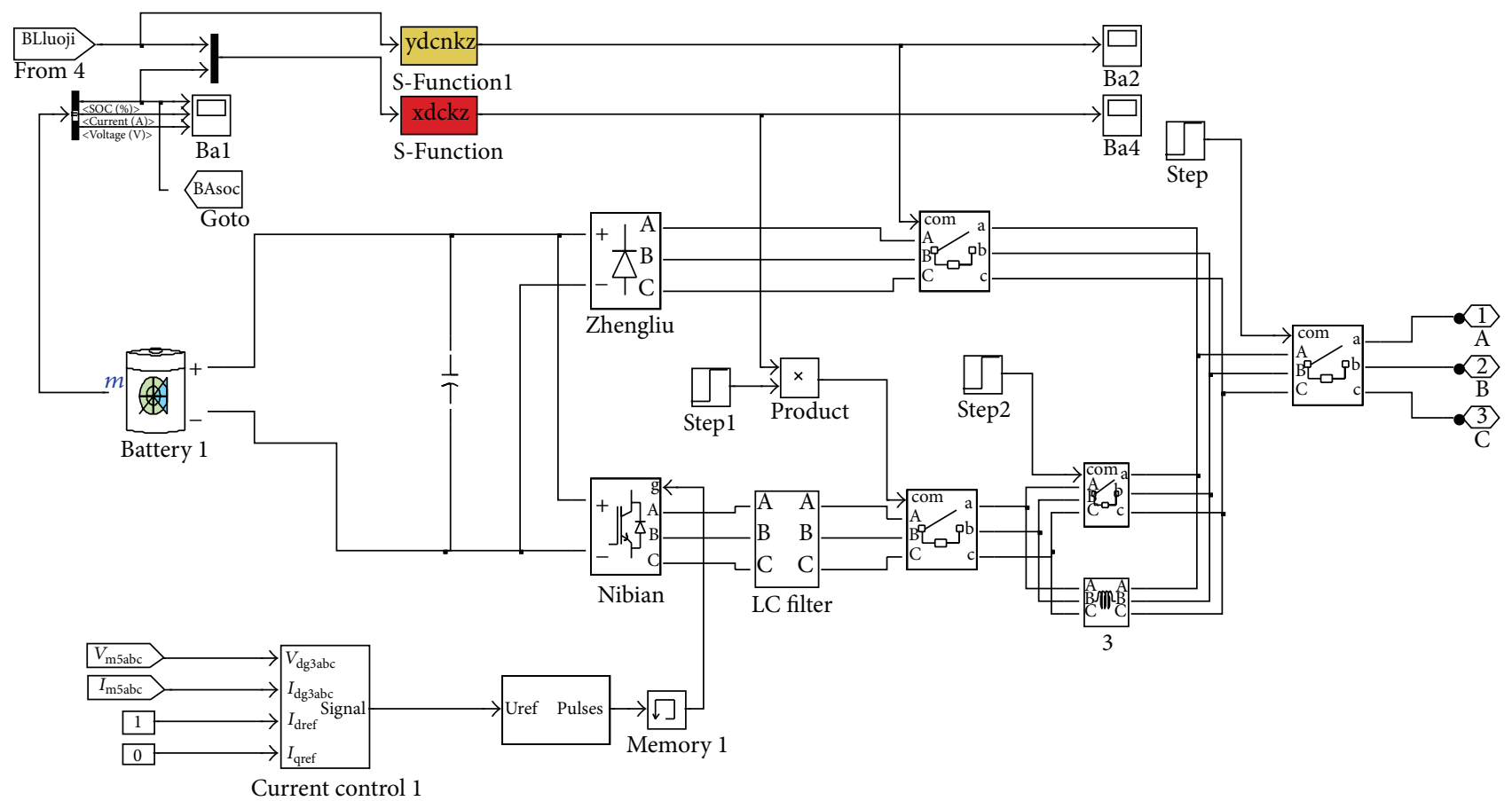

FIGURE 14: Simulation model of EV (DG3).

Diagrams of current control method and voltage control method of the inverter adopted are shown in Figures 15 and 16.

Figures 16 to 25 show output waves of an example simulation case where initialized SOC of EV is $80.05 \%$. Simulation events are listed in Table 1.
As shown in Figure 17, islanding of microgrid was detected in 1 cycle and changed to islanding control mode. Figure 18 shows that DG2 as main source in islanding mode works well to keep voltage and frequency stable. Figures 19 and 20 show that PV works in current source mode and provide continuous power of $10 \mathrm{~kW}$ while some fluctuation 


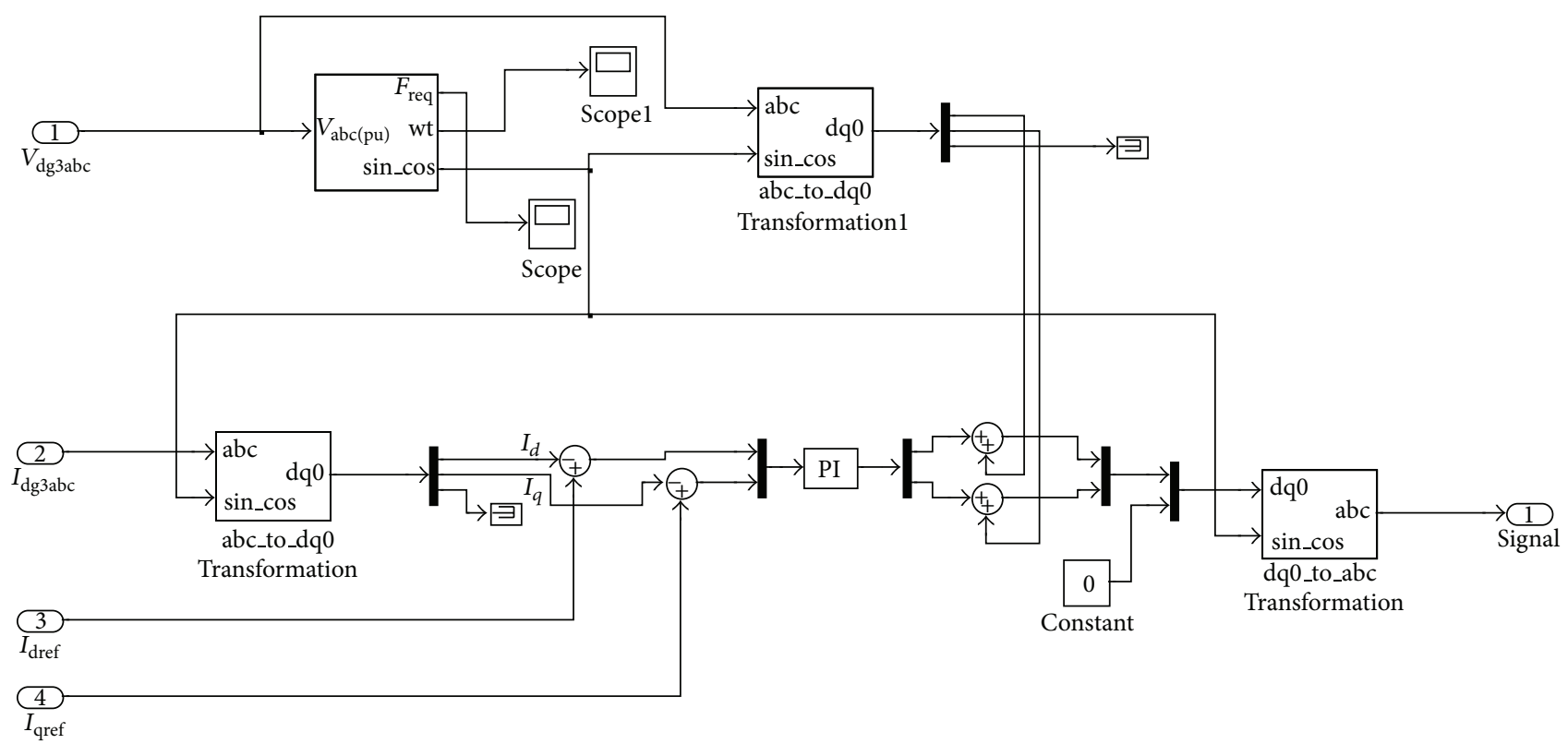

FIGURE 15: Diagram of current control in simulation.

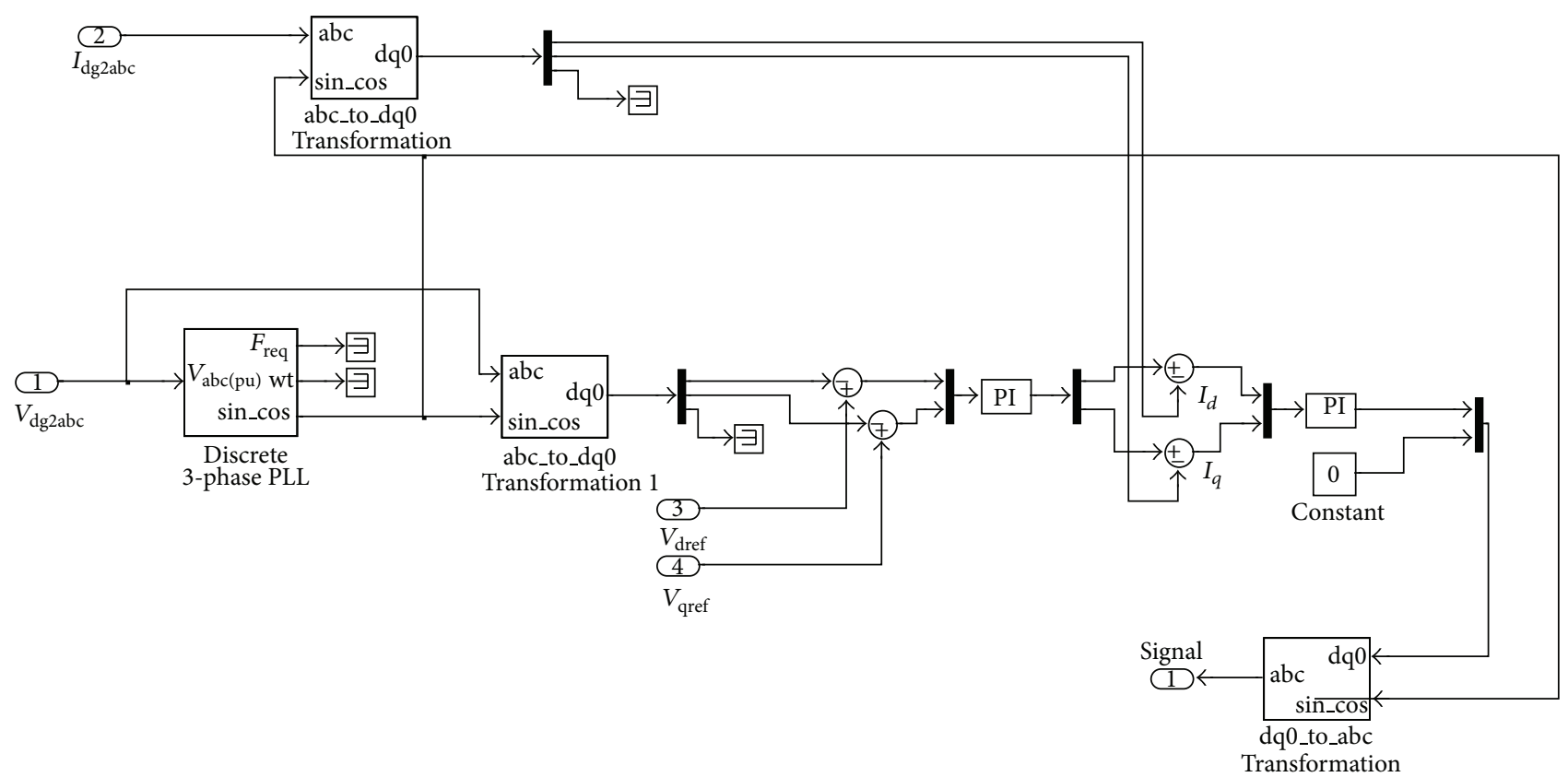

FIGURE 16: Diagram of voltage control in simulation.

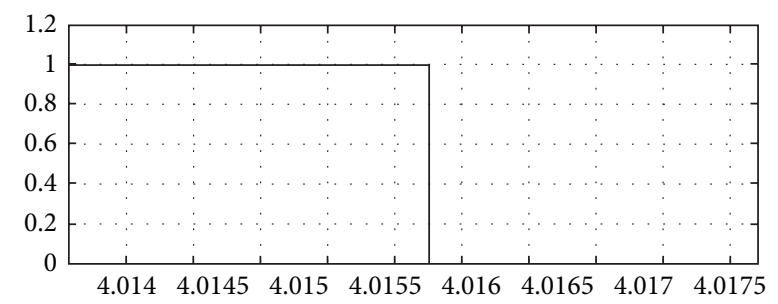

Time offset: 0

FIgURE 17: Output signal of microgrid island detection.

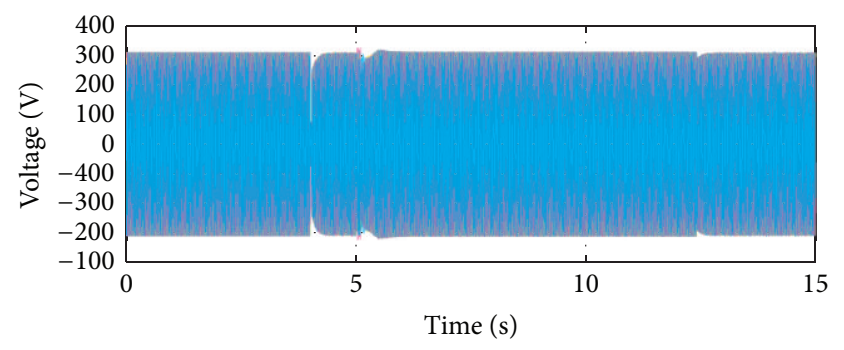

FigURE 18: Voltage wave of microgrid busbar. 


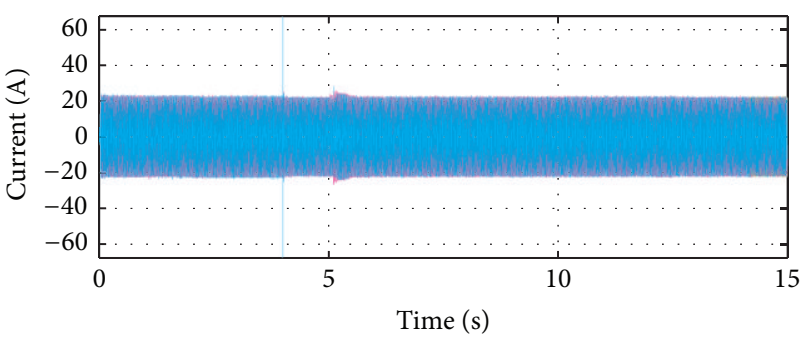

FIGURE 19: Current wave of DG1 (PV).

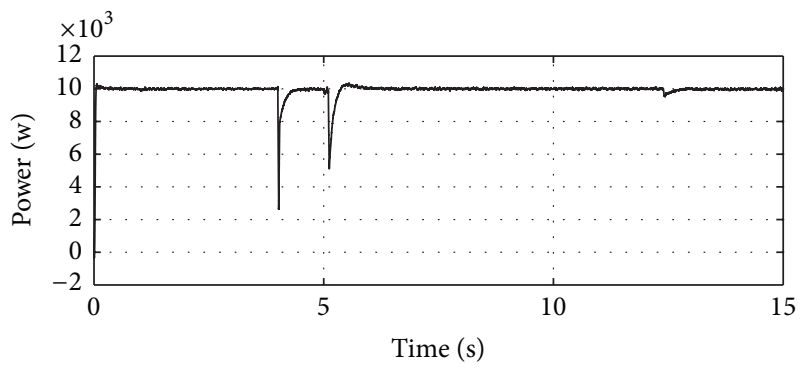

FIgURE 20: Active power output of DG1.

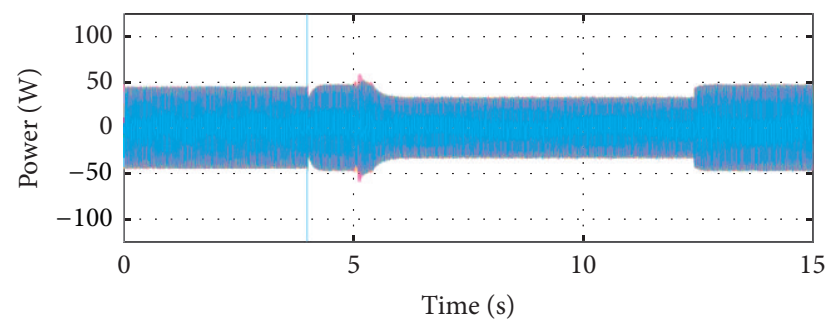

FIGURE 21: Current wave of DG2 (battery).

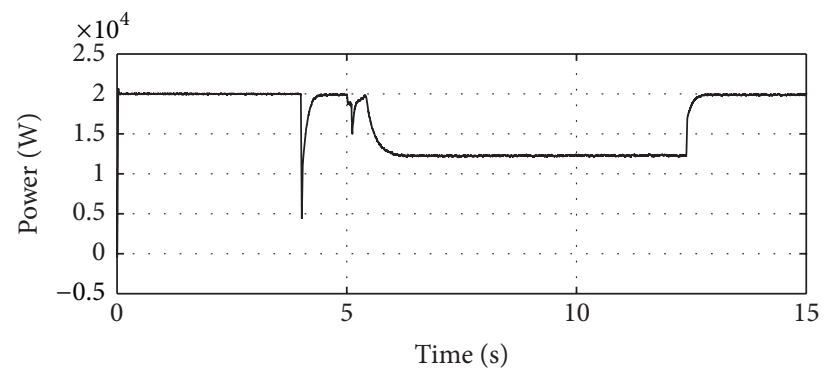

FIGURE 22: Active power output of DG2 (battery).

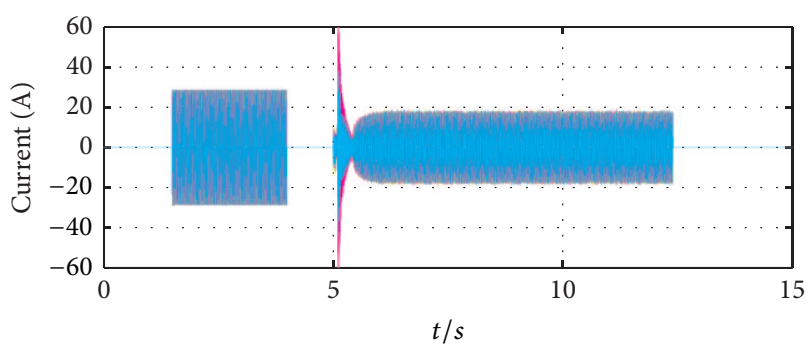

Figure 23: Current wave of DG3 (EV).

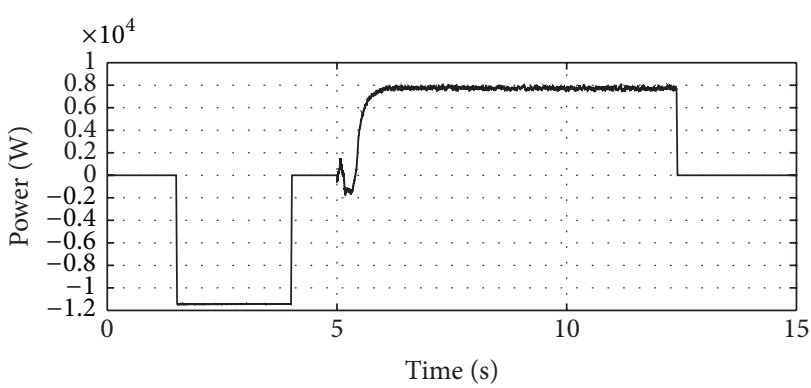

FIGURE 24: Active power output of DG3 (EV).

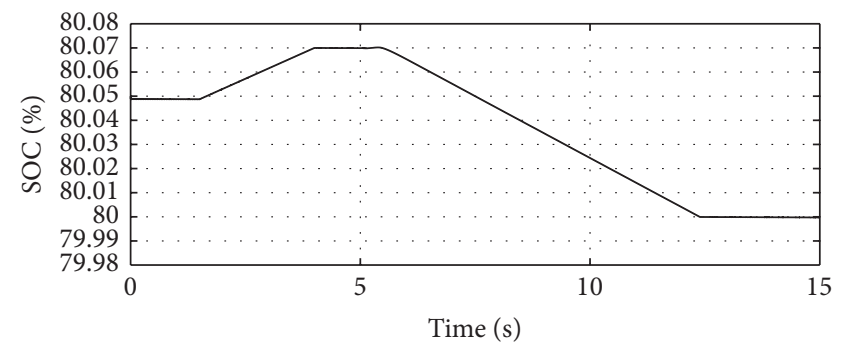

FIGURE 25: Real-time capacity of EV.

TABLE 1: Time list of simulation events.

\begin{tabular}{lc}
\hline Time $(\mathrm{s})$ & Event \\
\hline 1.5 & EV connected to grid as load \\
4 & Utility grid failure \\
5 & EV change to V2G mode \\
12.5 & EV exit \\
\hline
\end{tabular}

at $4 \mathrm{~s}$ and $5 \mathrm{~s}$ that utility grid failure and EV change to V2G mode. Figures 21, 22, 23, and 24 show that EV as current source provides power in islanding mode and decreases power output of main source. Figure 25 shows that EV will exit V2G mode when SOC reach lower limit (which is set to $80 \%$ in simulation).

4.2. Laboratory Platform of Microgrid with Photovoltaic and $E V$. A laboratory platform of microgrid with $25 \mathrm{~kW}$ photovoltaic, $50 \mathrm{kWh} / 25 \mathrm{~kW}$ lithium battery packs, $15 \mathrm{kWh} / 18 \mathrm{~kW}$ $\mathrm{EV}, 25 \mathrm{~kW}$ load simulator and $24 \mathrm{~kW}$ lighting loads was formed in BJTU as shown in Figure 26. The EV is a Tong Yue EV manufactured by Jianghuai Automobile China (JAC) with 50 Ah battery, 7 hours of charging time, rated power $18 \mathrm{~kW}$ and maximum power $42 \mathrm{~kW}$. Structure of the microgrid is shown in Figure 27, where battery inverter works in VSC mode when microgrid islanded, $I_{g}, I_{m 1}, I_{m 2}, I_{P}, I_{B}$ as directions shown in Figure 27 are currents of PCC, converter 1 , converter 2, PV, and battery. Control methods are adopted as in Section 3.3.

Experiments of parallel/islanding were carried out in different load status. Figures 28, 29, 30, 31, 32, 33, and 34 show the voltage/current wave, frequency wave, voltage amplitude wave, and power wave of one example experiment where in microgrid parallel status load power is $P_{l}=4.0 \mathrm{~kW}, Q_{l}=$ 


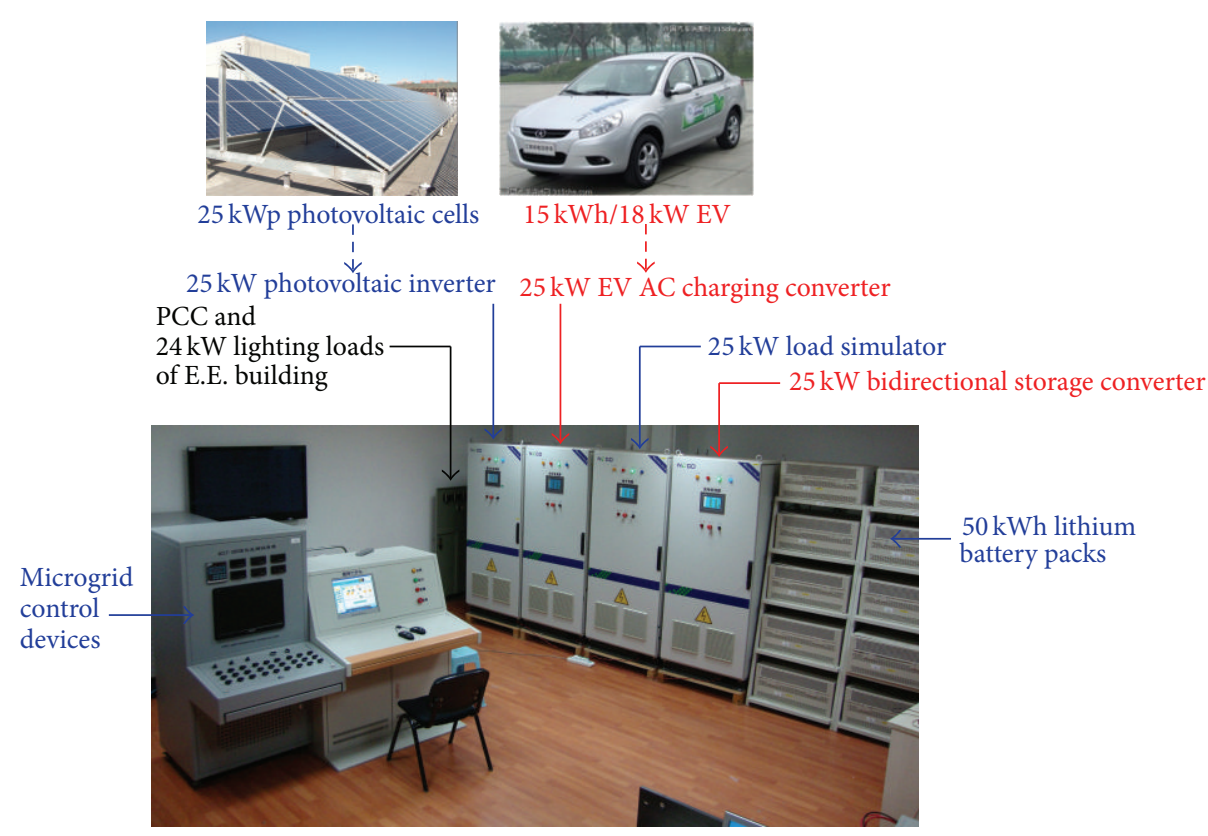

FIGURE 26: Laboratory platform of microgrid with photovoltaic and EV.

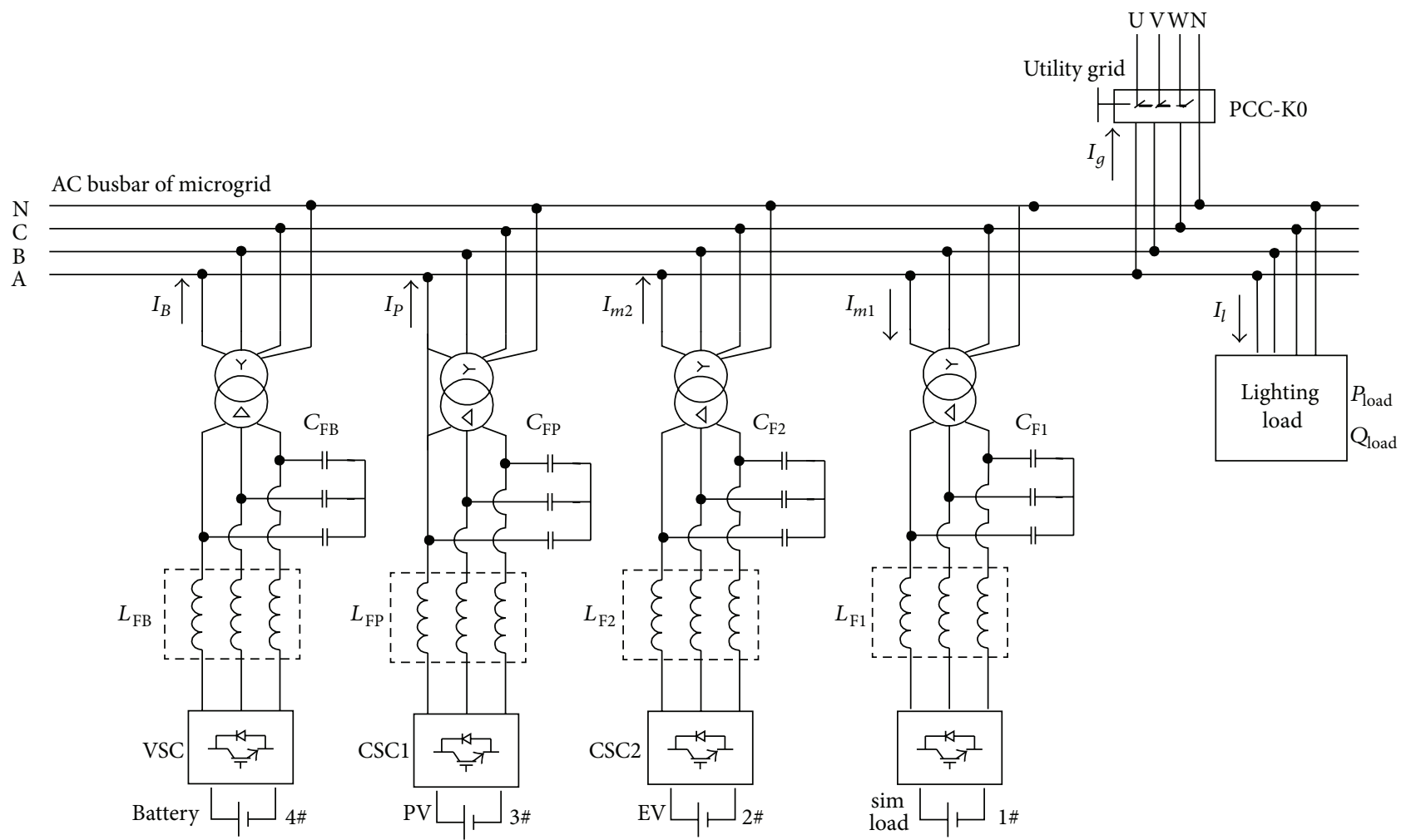

FIGURE 27: Structure of the Laboratory platform.

$2 \mathrm{kVar}$, sim-load power(1) is $P_{1}=8.0 \mathrm{~kW}, Q_{1}=0 \mathrm{kVar}, \mathrm{EV}$ (2) power is $P_{2}=-2.0 \mathrm{~kW}, Q_{2}=0 \mathrm{kVar}$ (charging), $\mathrm{PV}$ (3) output power is $P_{P 3}=5.1 \mathrm{~kW}, Q_{P 3}=0 \mathrm{kVar}$, and battery charging power is $P_{B 4}=-4.0 \mathrm{~kW}, Q_{B 4}=0 \mathrm{kVar}$ (charging). In islanding mode, load power is $P_{l}=4.0 \mathrm{~kW}, Q_{l}=2 \mathrm{kVar}$, sim-load power (1) is $P_{1}=8.0 \mathrm{~kW}, Q_{1}=0 \mathrm{kVar}, \mathrm{EV}$ (2) power is $P_{2}=11.0 \mathrm{~kW}, Q_{2}=1.5 \mathrm{kVar}$ (discharging), $\mathrm{PV}$ (3) output power is $P_{P 3}=5.1 \mathrm{~kW}, Q_{P 3}=0 \mathrm{kVar}$, and battery storage power is $P_{B 4}=1.0 \mathrm{~kW}, Q_{B 4}=0.5 \mathrm{kVar}$ (discharging). At the "second regulation" point, EV output power decrease as the SOC of EV has dropped to the point of low power output point; battery output power increases to balance the power. 


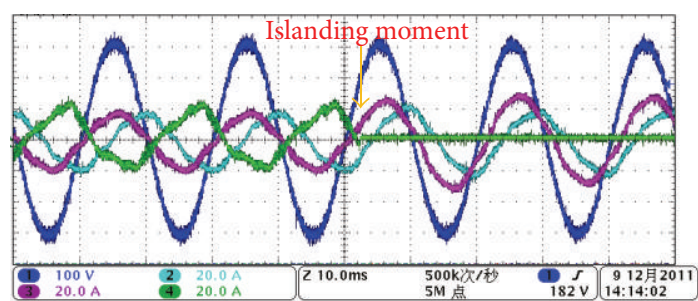

(a) Parallel to islanding

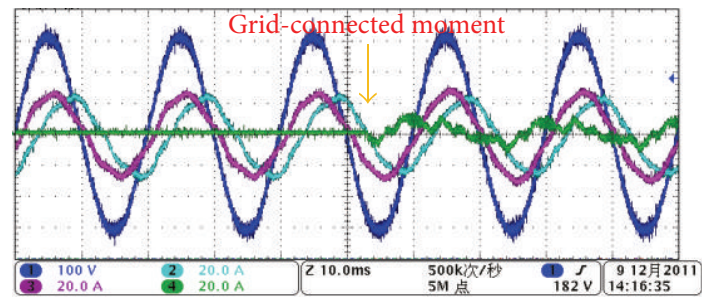

(b) Islanding to parallel

FIGURE 28: Voltage/current wave of parallel/islanding transfer $(\mathrm{CH} 1$ : phase A voltage, $\mathrm{CH} 2$ : phase A current of $I_{m 1}, \mathrm{CH} 3$ : phase A current of $I_{P}$, and CH4: phase A current at PCC $\left.\left(I_{g}\right)\right)$.

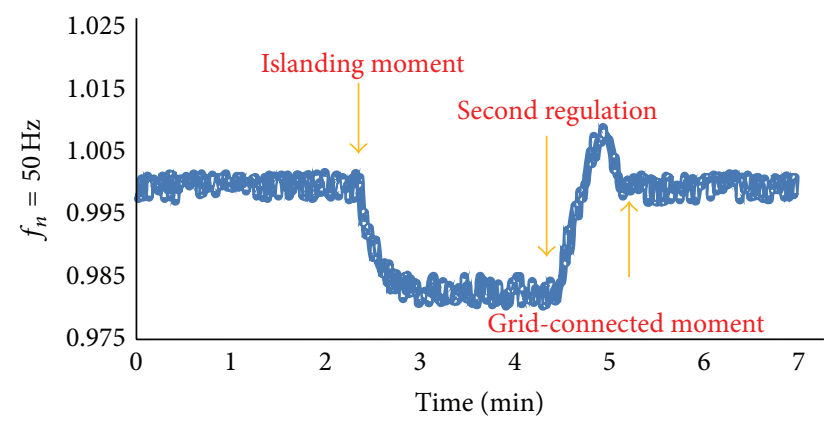

FIGURE 29: Frequency wave.

As we can see that using the control strategy proposed in this paper, maximum power output of renewable energy was utilized both under parallel-to-grid and islanding mode, and the stably operation time of microgrid under islanding was prolonged as a result of the participant of EV as power source.

\section{Conclusions}

This paper presented a control strategy for microgrid containing renewable energy and electric vehicles. The strategy uses current control mode for renewable energy generations under parallel-to-grid mode and uses master-slave grid control which elects battery storages as main power sources DGs and EVs as slave power source under islanding mode. Compared with other strategies, this strategy does not need to change working mode of DGs while transferring between parallel-to-grid and islanding and can fully use the power of DGs, immune to output power fluctuation of DGs, and prolong the stable running time of microgrid under islanding mode. According to simulation results and laboratory experiments, the proposed control strategy works

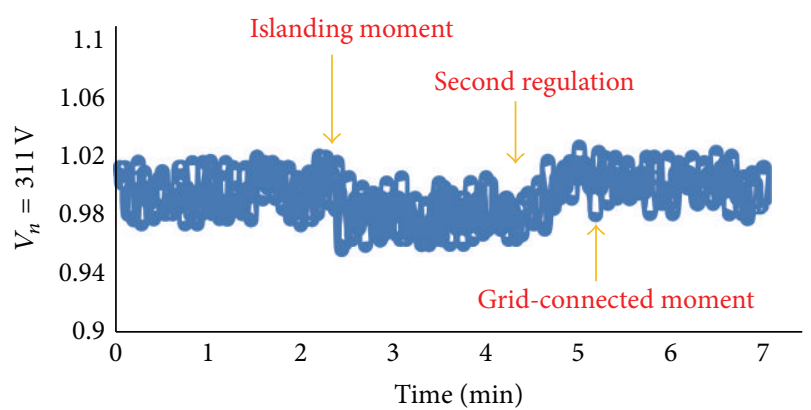

Figure 30: Voltage amplitude wave.

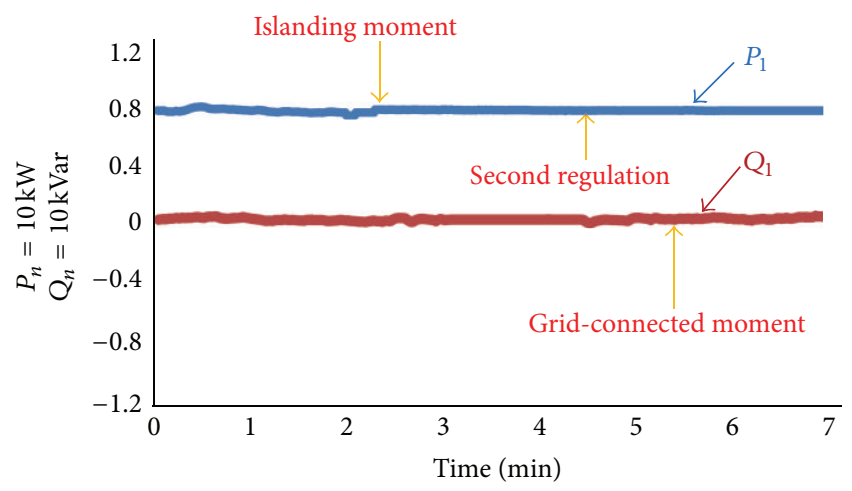

FIGURE 31: Power wave of converter 1.

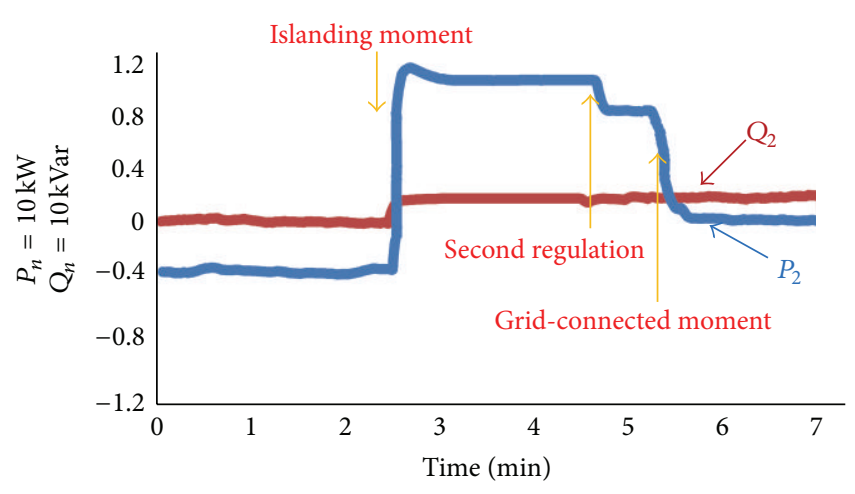

FIgURe 32: Power wave of converter 2.

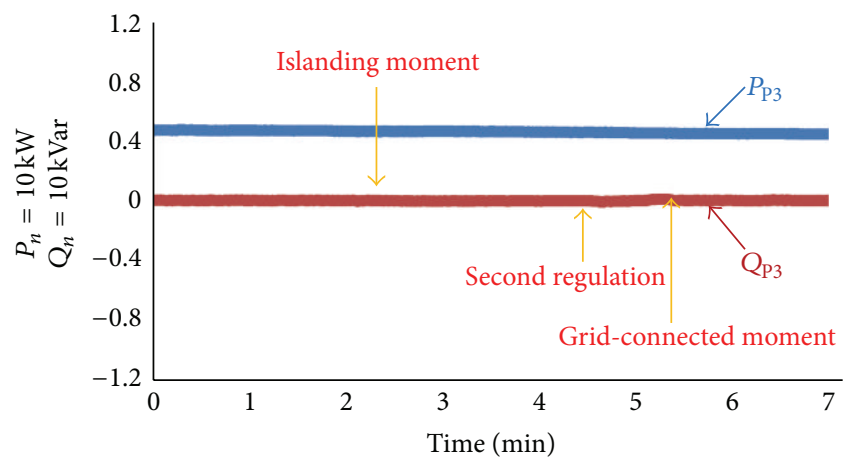

FIgURE 33: Power wave of converter 3. 


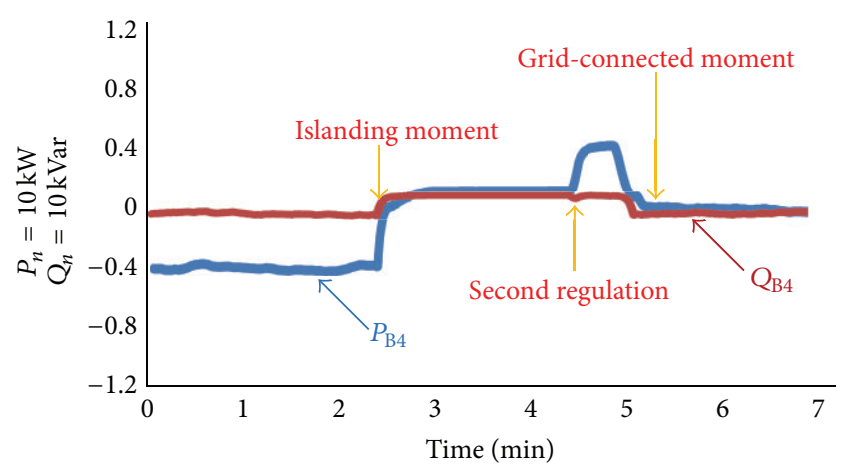

Figure 34: Power wave of converter 4.

well and provides maximum power output of renewable energy and stable and sustainable microgrid running under islanding mode. We hope that the strategy will beadopted for industrial applications.

\section{Acknowledgment}

The authors gratefully acknowledge the support of the National Natural Science Foundation of China, for financial support under Grant no. 51277009.

\section{References}

[1] C. W. Gellings, "The grid of the future: the need for technology and intelligence in the future power system," in Proceedings of the Technical Exhibition, Grid of the Future Symposium (CIGRE '12), Kansas City, Mo, USA, October 2012.

[2] W. Kempton and J. Tomić, "Vehicle-to-grid power implementation: from stabilizing the grid to supporting large-scale renewable energy," Journal of Power Sources, vol. 144, no. 1, pp. 280-294, 2005.

[3] F. Blaabjerg, R. Teodorescu, M. Liserre, and A. V. Timbus, "Overview of control and grid synchronization for distributed power generation systems," IEEE Transactions on Industrial Electronics, vol. 53, no. 5, pp. 1398-1409, 2006.

[4] Z. Xue-Mei, G. Jia-Sheng, C. Zhi-Gang, S. Cen, Q. ChaoKui, and F. Jian-Ping, "Thermodynamic model study of microturbine with MATLAB/Simulink," in Proceedings of the International Conference on Consumer Electronics, Communications and Networks (CECNet '11), pp. 913-918, Ningbo, China, April 2011.

[5] B. Chen, "Research and development of fuel cell technology in China," in Proceedings of the Asia-Pacific Power and Energy Engineering Conference (APPEEC '11), pp. 1-4, Wuhan, China, March 2011.

[6] E. Denny and M. O’Malley, "Wind generation, power system operation, and emissions reduction," IEEE Transactions on Power Systems, vol. 21, no. 1, pp. 341-347, 2006.

[7] H. Valderrama-Blavi, J. M. Bosque, F. Guinjoan et al., "Power adaptor device for domestic DC microgrids based on commercial MPPT inverters," IEEE Transactions on Industrial Electronics, vol. 60, no. 3, pp. 1191-1203, 2013.

[8] H. Yan, Z. Zhou, and H. Lu, "Photovoltaic industry and market investigation," in Proceedings of the 1st International Conference on Sustainable Power Generation and Supply (SUPERGEN '09), pp. 1-4, Nanjing, China, April 2009.

[9] S. M. Moosavian, N. A. Rahim, and J. Selvaraj, "Photovoltaic power generation: a review," in Proceedings of the IEEE 1st Conference on Clean Energy and Technology (CET '11), pp. 359363, Kuala Lumpur, Malaysia, June 2011.

[10] E. J. Simburger, "Is a residential photovoltaic system a cost effective investment for the homeowner?" in Proceedings of the 34th IEEE Photovoltaic Specialists Conference (PVSC '09), pp. 2336-2339, Philadelphia, Pa, USA, June 2009.

[11] B. Subudhi, R. Pradhan, B. Subudhi et al., "A comparative study on maximum power point tracking techniques for photovoltaic power systems," IEEE Transactions on Sustainable Energy, vol. 4, no. 1, pp. 89-98, 2013.

[12] G. Coppez, S. Chowdhury, and S. P. Chowdhury, "Impacts of energy storage in distributed power generation: a review," in Proceedings of the International Conference on Power System Technology: Technological Innovations Making Power Grid Smarter (POWERCON '10), pp. 1-7, Hangzhou, China, October 2010.

[13] C. Battistelli, L. Baringob, and A. J. Conejob, “Optimal energy management of small electric energy systems including V2G facilities and renewable energy sources," Electric Power Systems Research, vol. 92, no. 1, pp. 50-59, 2012.

[14] R. H. Lasseter and P. Paigi, "Microgrid: a conceptual solution," in Proceedings of the IEEE 35th Annual Power Electronics Specialists Conference (PESC '04), pp. 4285-4290, Aachen, Germany, June 2004.

[15] R. H. Lasseter, "CERTS microgrid," in Proceedings of the IEEE International Conference on System of Systems Engineering (SOSE '07), pp. 1-5, San Antonio, Tex, USA, April 2007.

[16] R. Joan, L. Alvaro, and B. Frede, "Control of power converters in AC microgrids," IEEE Transactions on Power Electronics, vol. 27, no. 11, pp. 4734-4749, 2012.

[17] R. Lin, P. Yeh, and C. Liu, "Positive feed-forward control scheme for distributed power conversion system with multiple voltage sources," IEEE Transactions on Power Electronics, vol. 27, no. 7, pp. 3186-3194, 2012.

[18] M. A. Herran, J. R. Fischer, S. A. Gonzalez et al., "Adaptive dead-time compensation for grid-connected PWM inverters of single-stage PV systems," IEEE Transactions on Power Electronics, vol. 28, no. 6, pp. 2816-2825, 2013.

[19] A. E. Leon, J. A. Solsona, and M. I. Valla, "Control strategy for hardware simplification of voltage source converter-based power applications," IET Power Electronics, vol. 4, no. 1, pp. 3950, 2011.

[20] J. Kim, J. M. Guerrero, P. Rodriguez, R. Teodorescu, and K. Nam, "Mode adaptive droop control with virtual output impedances for an inverter-based flexible AC microgrid," IEEE Transactions on Power Electronics, vol. 26, no. 3, pp. 689-701, 2011.

[21] L. Guo, C. Wang, L. Guo, and J. Cao, "Dynamical characteristic of MicroGrid with peer to peer control," in Proceedings of the China International Conference on Electricity Distribution (CICED '08), pp. 1-7, Guangzhou, China, December 2008.

[22] P. Yuan, L. Pei-Qiang, L. Xin-Ran et al., "Strategy of research and application for the microgrid coordinated control," in Proceedings of the International Conference on Advanced Power System Automation and Protection, pp. 873-878, Beijing, China, 2011. 
[23] B. Zhao, X. Zhang, and J. Chen, "Integrated microgrid laboratory system," IEEE Transactions on Power Systems, vol. 27, no. 4, pp. 2175-2185, 2012.

[24] V. Badescu, "Dynamic model of a complex system including PV cells, electric battery, electrical motor and water pump," Energy, vol. 28, no. 12, pp. 1165-1181, 2003.

[25] S. Jiang, D. Cao, Y. Li, and F. Zheng Peng, "Grid-connected boost-half-bridge photovoltaic microinverter system using repetitive current control and maximum power point tracking," IEEE Transactions on Power Electronics, vol. 27, no. 11, pp. 47114722, 2012. 


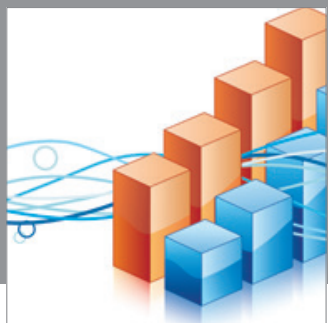

Advances in

Operations Research

mansans

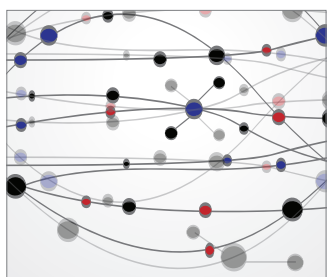

The Scientific World Journal
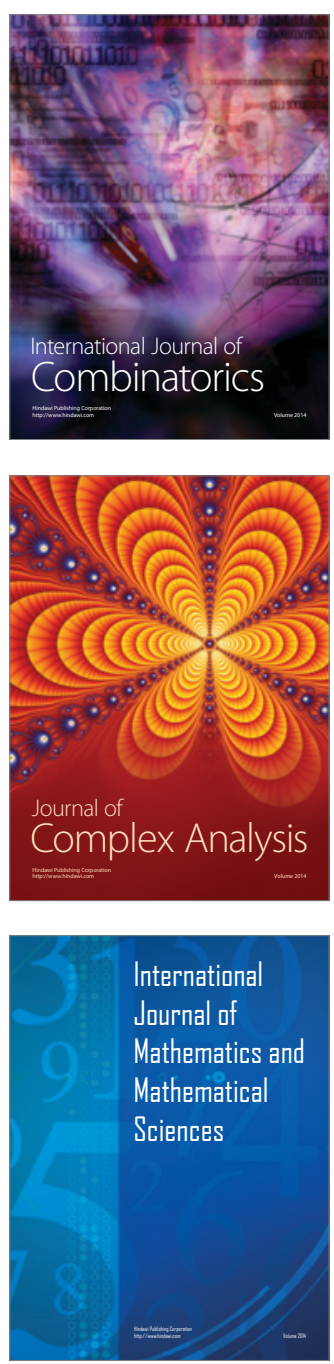
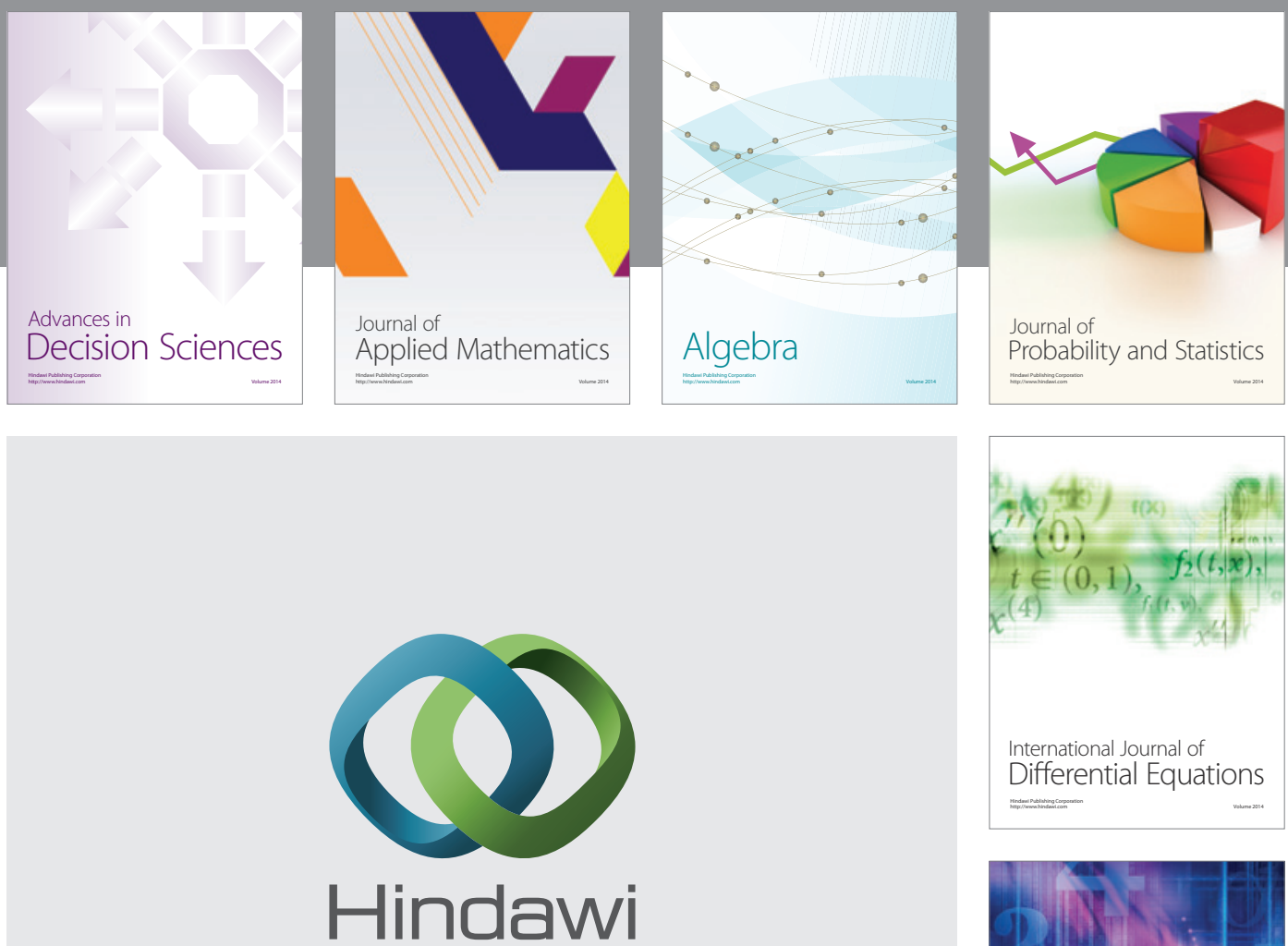

Submit your manuscripts at http://www.hindawi.com
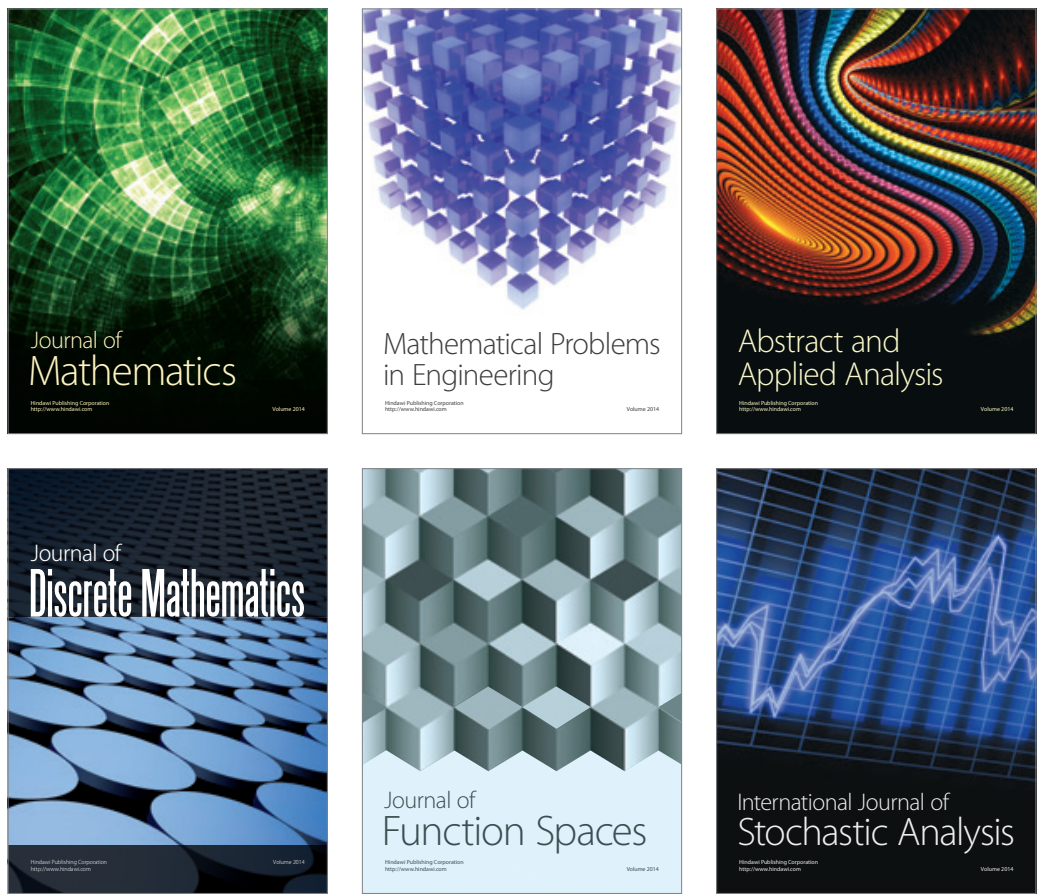

Journal of

Function Spaces

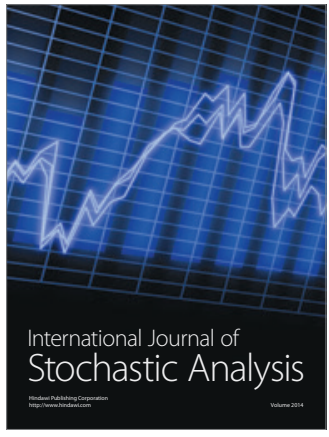

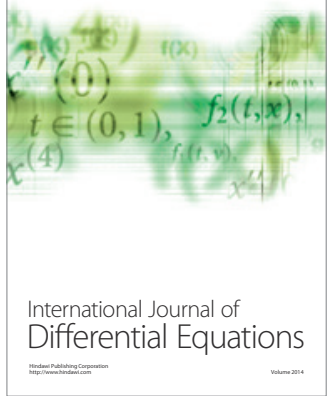
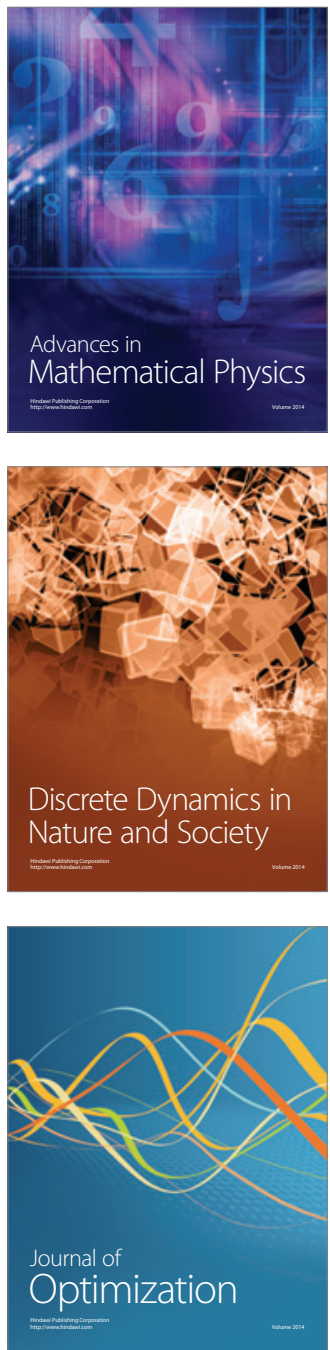